University of Missouri-Kansas City School of Law

UMKC School of Law Institutional Repository

The Internet, Regulation and the Market for Loyalties: An Economic Analysis of Transborder Information Flow

Paul D. Callister

Follow this and additional works at: https://irlaw.umkc.edu/faculty_works

Part of the Computer Law Commons 
The enclosed article is subject to copyright (@ 2002) with all rights reserved by the University of Illinois Board of Trustees. Permission was granted to the author by the journal's Editor-in-Chief, Professor Jay Kesan, to post the article to digital repositories. Further copying or distribution of this article requires permission. 


\section{THE INTERNET, REGULATION AND THE MARKET FOR LOYALTIES: AN ECONOMIC ANALYSIS OF TRANSBORDER INFORMATION FLOW}

Paul D. Callister

As the Internet has gained prevalence, attention has turned to its regulation. Indeed, regulation proves to be a unique and complex problem, given the Internet's lack of traditional borders and boundaries. Highlighting possible avenues of regulation, the author discusses neo-classical economic theory, specifically Monroe E. Price's "market for loyalties" theory. Although originally applied to the regulation of broadcasting, the author contends that the "market for loyalties" theory can also be applied to the Internet. Building on Professor Price's pioneering analysis, the article extends the theory to examine market elasticity's effect on the loss of monopoly control over information flow (as a result of the Internet).

Because the fundamental nature of information defies traditional legal and economic models, regulation of the Internet is problematic. In addition, the sheer scale, social aspects, and functional design of the Internet itself make effective regulation difficult. Governments are also faced with the dilemma of limiting Internet access while still leveraging its economic benefits. Nonetheless, governments have attempted to regulate the Internet through content filtering, Internet surveillance, and self-policing.

By applying the "market for loyalties" theory, the article analyzes the behavior of states in regulating transborder information flow and predicts the consequences of unsuccessful regulation. After summarizing the theory and setting forth its elements, the author explores the relationship of exchange between identity and the competition for loyalty and identifies factors which destabilize the status quo (in terms of diminished loyalty). Indeed, in the interest of

* Law Reference Librarian \& Assistant Professor of Library Administration, University of Illinois College of Law. B.A., Brigham Young University, 1988; J.D., Cornell Law School, 1991; M.S. (Library and Information Science), University of Illinois at Urbana-Champaign, 2000. The author would like to thank the following people for their assistance, encouragement and comments: Terry Weech, Peter Hook, Paul Healey, Jay Kesan, Kimberly Davison, Michael Robak, and Virginia Callister. 
self-preservation, the government asserts monopoly power over the market for loyalties. Thus, regulatory schemes change when the balance of power shifts, or when existing regulation proves inadequate to maintain the status quo.

By comparing the efficiency of two different markets, citing Singapore and China, and considering the role of elasticity in each market, the article details the possible ramifications of a loss of monopoly control for each market. Because elasticity is a function of the prior penetration into the market of competing products (or identities), the author concludes that the most restrictive regimes face the greatest turmoil (as expressed in decline in loyalty resulting from increased competition). Finally, the author delineates the "market for eyeballs" theory and why the "market for loyalties" as expanded in his discussion provides a more thorough analytical framework.

I. CAN THE INTERNET BE REGULATED?

A. Why It May Not Be Possible to Regulate the Internet..............62

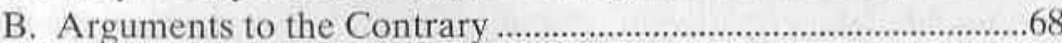

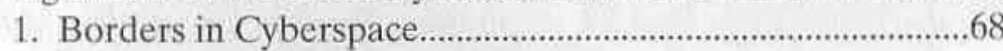

2. Government Filtering …….................................................74

3. Technological and Regulatory Response to

Demands of Business and Commerce ...................................78

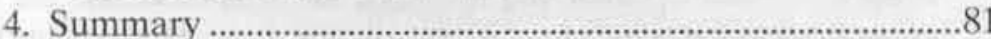

II. MARKET FOR LOYALTIES THEORY ………………………………….......81

A. Summary of Professor Price's Application of

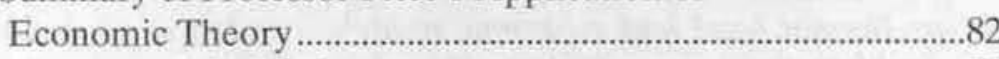

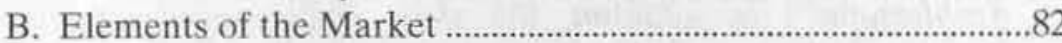

C. Identity and the Competition for Loyalty.....................................84

D. Destabilizing Influences - Competing Groups and

Western Commercial Culture ..................................................... 85

1. Competing Internal Groups....................................................85

2. Effect of Western Commercial Broadcasting and

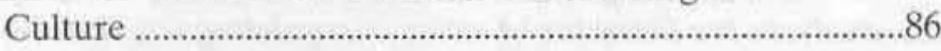

E. Regulation to Preserve Monopoly (or Oligopoly) of

Identity

F. Reflecting the Existing Power Structure ……………………........8

III. APPLICATION OF ECONOMIC MODEL TO EXPLAIN

REGULATION OF THE INTERNET.

A. Consequences if Government is Unable to Regulate

According to Economic Model.

1. General Predictions .........................................................90

2. Predictions for Singapore's Efforts .......................................92

3. Predictions for China's Efforts ............................................
4. Extrapolating from Elasticity - Additional Theorizing......96 B. Comparison to the "Market for Eyeballs,"

"Collective Action" Problems, and the Problem

of "Externalities"

IV. CONCLUSION

V. APPENDIX

The problem the Internet poses for law is not simply whether the Internet can be regulated, but more theoretically, what are the consequences if it cannot? In an attempt to answer this question, this paper will apply neo-classical economic theory to governments as if they were monopolies and explore the consequences once their monopoly positions are destroyed (because of the inability to regulate information flow). Specifically, this paper will consider the theory of Monroe E. Price, ${ }^{2}$ known as the "market for loyalties" theory, which has been previously applied by him in the context of international broadcasting regulation. After explaining the theory and its initial application by Professor Price, the paper will illustrate how the "market for loyalties" theory may be extended. The extension will be performed by considering elasticity to permit predictions of the Internet's impact on authoritarian governments that fail to regulate the Internet, even while reducing such analysis to a mathematical function. Interestingly, those regimes that historically restrict information flow the most are susceptible to the greatest instability as a result of new information technologies such as the Internet. The appropriateness of the neo-classical theory in light of the problem of externalities and collective action is also reviewed. This paper's analysis of the consequences of the loss of monopoly control over information flow as a result of the Internet, and the effect of market elasticity upon those consequences, is new and has not been previously considered by Professor Price (whose work instead focuses on the regulation of broadcasting).

The term "information" is used instead of "data" (typically we read of "transborder data flow") because "information" represents some level of order, as is colly we read of "transborder data whether via satellite or radio broadcast, Internet, or the printed word. See, in. H. HRLA CUPVELAND, The Knowledge Dymamic, in THE KNOWLEDGE EXECUTIVE 19,22 (1985) ("In its narrower sense information is organized data - or Knized by others, not by me,"). See also Tom Stonier. Towardse information is organized data-organized by others, not by me."). See also Tom Stonicr, Towards a General Theory of Information II: Information and Entropy, 41 ASLIB PROCEEDINGS 41,43 (1989)
("Information has as much physical reality as do matter and energy: what mass is to matter, or ("Information has as much pliysical reality as do matter and energy: What mass is to matter, or momentum to mechanical energy, organization is to information."): Robert M. Losee, A Discipline
Independent Definition of Information, 48 J. AM Soc'Y INFO. SCL. 254, 267 (1997) ("Information may Independent Defimition of Information, 48 J. AM SOC Y INFO. SCL. 254, 267 (1997) ("Information may fe understood as the value attached or instantiated to a characteristic or variable returned by a be read broadly to include data.

2. Monroe E. Price is the Joseph and Sadie Danciger Professor of Law and Director of the Howard M. Squadron Program in Law. Media and Society and a former Dean of the Cardozo School of Law.

Professor Price does give limited consideration to the Internet. See infra note 139. 


\section{CAN THE INTERNET BE REGULATED?}

The object of this paper is to explore the effect of loss of monopoly control by governments and power elites over information flow as a result of the Internet. However, that question assumes that there is a loss of monopoly control (i.e., that governments find it difficult, if not impossible, to regulate the Internet). The issue in question is information blockage. More specifically, the issue of regulation is limited to whether (i) content on the Internet can be controlled and (ii) access to that content can be restricted. The issue is not whether the behavior of specific individuals on the Web may be monitored, disciplined, censored or otherwise controlled, but whether there is significantly increased information flow to a society at large, which cannot be blocked by its government. Consequently, discussion of Internet regulation will not generally dwell on privacy (e.g., the U.S. Carnivore data surveillance system, employee e-mail monitoring or the European Union Directive on Data Protection), copyright infringement, or computer security, but simply on whether, in terms of content, the flow of information can be effectively controlled. Consideration will be given to arguments on both sides of the issue regarding the ability to regulate the Internet.

\section{A. Why It May Not Be Possible to Regulate the Internet}

The Internet, by its very nature, is difficult to regulate.

Originally developed by the United States Department of Defense to maintain communications between critical agencies in times of war, the Internet was designed with sufficient flexibility to counter even the most determined blocking efforts. It has thus become an axiom among Internet users that "the Internet interprets censorship as damage and routes around it."

The difficulty of regulating such information flow quickly becomes apparent. Even when an Internet service provider ("ISP") bans a site, usually as a result of threatened government action (which often results in banning a large number of sites that are not objectionable), the typical response from the Internet community is the "creation of 'mirror sites' in unrestricted areas of the Internet. ${ }^{16}$ Particularly problematic is the lack

4. With respect to the EU Directive on data protection. see Eur. Parl. \& Council Directive 95/46, 1995 O.J. (L 281) $31-50$

5. John T. Delacourt. Recent Development. The International Impact of Internet Regulation, 38 HARV. INT'L L.J. 207, 217-18 (1997). Delacourt attributes the axiom to John Gilmore, a Silicon Valley engineer. Id at n. 60 .

6. Id. at 214. For additional examples of the use of mirror sites, see, e.g. Danny Gittings, Beijing Tries, but Fails, to Gag Internet Hosts, GUARDIAN, June 8, 2002, at 20, available at LEXIS. News Library, News Group File, Most Recent Two Years; Bernice Yeung. Babes in Toyland; Two Hackers Piss Off Mattel and Spawn an Internet Legal Imbroglio, SAN FRANCISCO WKLY.. May 17. 2000, available at LEXIS, News Library. News Group File. Most Recent Two Years; Zimbabwe: Using
E-Mail to Sidestep Harare's Censors, AFR. NEWS, Mar. 6. 2002, available at LEXIS, News Library, of geographic location (a prerequisite for legal jurisdiction and enforcement) of information on the Net.

[T] he determined seeker of prohibited communications can simply reconfigure her or his connection to appear to reside in a different location, outside the particular locality, state or country. Because the Net is engineered to work on the basis of "logical" not geographic locations, any attempt to defeat the independence of messages from physical locations would be as futile as an effort to tie an atom and a bit together.

In many respects, the resistance of the Internet to regulation is based on the nature of information itself: fluid, leaky, replicable, intangible, expandable, compressible, transportable, omnipresent, and shareable, etc. Such qualities are alien to traditional legal and economic models, making regulation difficult."

While there are Internet "realists," such as Jack L. Goldsmith, who downplay the differences of cyber and "real" space, ${ }^{10}$ even Professor Goldsmith acknowledges: "[T]he enforceable scope [of law] is relatively narrow. It extends only to individual users or system operators with presences and assets in the enforcement jurisdiction ...." Other cyber law experts are much more skeptical of the ability to regulate the

News Group File, Most Recent Two Years; Barb Palser, The Great Online Wall. AM. JouRNAuISM REV., Nov., 2001, at 74, available at LEXIS, News Library, News Group File, Most Recent Two Years: Sam Costello, Attrition.org Stops Mirroring Web Site Defacements. INFOWORLD DAll Y NEWS, May 22. 2001, available at LEXIS, News Library, News Group File, Most Recent Two Years; John Schwartz, Hacker Defaces Pro-Israel Web Site as the Mideast Conflict Expands Into Cyberspace, N.Y. TiMEs, Nov. 3, 2000, at A15, available at LEXIS. News Library, News Group File, Most Recent Two Years.

7. David R. Johnson \& David G. Post, The Rise of Law on the Global Network, in BORDERS IN CYBERSPACE 3,9 (Brian Kahin \& Charles Nesson eds., 1997).

8. See Cleveland, supra note 1 , at 29-33

9. Harla Cleveland points to a conceptual crisis surrounding information, which directly applies to the Internet:

What's also new is a theory crisis, a sudden sense of having run out of our basic assumptions. We have carried over into our thinking about information (which is to say symbols) concepts developed for the management of things - concepts such as property, depreciation. monopoly, market economics, the class struggle, and top-down leadership

The assumptions we have inherited are not producing satisfactory growth with acceptable equity in either the capitalist West or the socialist East.... Maybe it would help if we stopped looked hard instead at what makes it so special.

1d. at 28 . Although Harla Cleveland and this author may differ in opinion as to the viability of economic analysis in the information age, the nature of information is fundamentally different from the traditional kind of thinking addressed by economic models and legal systems. In fact, for one theorist, information is not so much a thing as it is a "physical property of the universe as 'real" as are matter and energy." Stonier, supra note 1, at 54. Thinking about information and the Internet in these terms may have profound implications on our legal and economic systems.

10. See Jack L. Goldsmith. Against Cyberanarchy, 65 U. CH1. L. REV. 1199, 1216-21 (1998) [hereinafter Against Cyberanarciy]; Jack L. Goldsmith \& Alan O. Sykes, The Internet and the Dormant Commerce Clause, YALE L.J. 785 (2001) ("[e]vents during the past five or so years have demonstrated that this conception of the Internet is wrong, or is at least incomplete.").

11. Against Cyberanarchy, supra note 10, at 1220 . 
Internet." "Our argument, rather [in contrast to Professor Goldsmith], is that the Internet and other related communications technologies cause those spillover effects from cyberspace to real space to be distributed more or less at random with respect to physical geography." ${ }^{13}$ This last criticism again is indicative of the nature of information-it is not dependent upon physical space.

Another critical aspect of the problem is the volume of Internet traffic and use, which makes effective monitoring difficult, if not impossible:

Individual electrons can easily, and without any realistic prospect of detection, "enter" any sovereign's territory. The volume of electronic communications crossing territorial boundaries is just too great in relation to the resources available to government authorities to permit meaningful control. U.S. Customs officials have generally given up. ${ }^{14}$

True, there is the FBI's Carnivore digital surveillance system and the open source alternative Altivore, ${ }^{15}$ but these systems are only capable of targeting specific individuals via a specific medium such as e-mail or online shopping. The system will not work to monitor Net traffic on any significant scale. ${ }^{16}$

Contemplating the sheer size of the Internet is akin to grasping the dimensions of the universe. A recent study by the School of Information Management Study at the University of California at Berkeley tried to estimate the Web's size:

In 2000 the World Wide Web consisted of about 21 terabytes [10 12 bytes] of static HTML pages, and is growing at a rate of $100 \%$ per year. Many Web pages are generated on-the-fly from data in

12. See, e.g., Johnson \& Post, supra note 7: David G. Post, What Larry Doesn't Get: Code, Law, and Liberty in Cyberspace, 52 STAN. L. REv. 1439 (2000) [hereinafter What Larry Doesn't Get]; David Decentralized Decision-Making in Compler Systems, 73 Cory Continent"; Towards A New Theory Of Chaos Prevailing]: Dan L. Burk, Federalism in Cyberspace. 28 CONV. LEV. 1055 (1998) [hereinafter Reidenberg, Governing Networks and Rule-making in Cyberspace, 45 EMORY L.J. 911 (1996);

13. Chaos Prevailing. supra note 12, at 1086 n. 64.

14. Johnson \& Post. supra note 7, at 8 .

15. MI5 'Black Box' Signals RIP Privacy Scare. NEWSwIRE (VNU), Feb. 7, 2001, available at 2001 WL 7307451 (also reports on rumor of system built by British intelligence).

16. See IIT RESEARCH INST., INDEPENDENT TECHNICAL REVIFW OF CARNIVORE SYSTEM: FINAL REPORT 4-4 (Dec. 8, 2000), available at http://Www.usdoj.gov/jmd/publications/VORE SYSTEM: An explanation of the limitations of the systems states:

Carnivore does not come close to having enough power "to spy on almost everyone with an email account." In order to work effectively it must reject the majority of packets it mene with an email monitors only the packets traversing the wire to which it is connected. Typically, this wire is a network segment handling only a subset of a particular ISP's traffic. The main limitation is the amount of storage. For example, if Carnivore were collecting all traffic on a link that has a steady 25.Mbps traffic rate, the 2-Gbyte Jaz disk will be full in about 11 minutes.... Even if collecting to fast hard drives the amount of data to be recorded would quickly overflow the amount of Id. databases, so the total size of the "deep Web" is considerably larger.

Although the social impact of the Web has been phenomenal, about 500 times as much email is being produced per year as the stock of Web pages. It appears that about 610 billion emails are sent per year, compared to 2.1 billion static Web pages. Even the yearly flow of Usenet news is more than 3 times the stock of Web pages.

The same study also stated that there would be an estimated four billion individual Web pages by 2001 .

In response to concerns about the undesirable effects of the Internet, whether perceived or actual, Singapore fashioned an "Internet Code of Practice" in 1996, ${ }^{19}$ designed to hold ISPs accountable for providing access to objectionable materials. However, Singapore recognizes the impossibility of totally blocking undesirable material. One legal scholar commented on this fact, noting the role of a "best endeavors" standard for ISPs in Singapore:

Although the implication of the "best endeavors" proviso [i.e., ISPs are required to exert "best endeavors" in screening objectionable material] is not immediately clear, the special circumstances of the Internet, the rapidity of communications and the difficulty of harnessing the continuous flow for regulatory purposes, may be taken into account in determining whether a licensee was or was not in breach of [the Internet Code of Practice]. Moreover, considering that cyberspace is increasingly proving ungovernable even by the standards of the best "cubercops" imaginable, the degree of allowances for failure envisaged by the Code may indeed be wider than might appear. Compared with the best alternative of shutting out any "unwanted information" through a total blackout (the very notion of which the government has repeatedly come out against). the requirement of "best efforts" in a reality which is characterized by dynamism and unpredictability and, therefore, enormously

17. Peter Lyman et al., How Much Information?: Executive Summary, at http://www.sims.berkeley.edu/how-much-info/summary.html (last modified Oct. 20,2000$)$. The entire
report can be downloaded at hutp://www,sims.berkeley.edu/research/projects/how-much-info/howmuch-info.pdf.

18. Peter Lyman et al.. How Much Information?: Internet - WWW Details at http://www.sims. berkeley.edu/research/projects/how-much-info/internet/wwwdetails.html (last modiffed Oct. 24. 2000). Indeed, if the amount of information available on the "deep" Web (i.e., the unsearchable, but accessible, portion of the Web) is considered, the total is about eight petabytes (1015 bytes) or about four times the total information available in all academic research libraries in the U.S. Lyman et al. How Much Information? at hittp://www.sims. berkeley, edu/research/projects/how-muchinfo/datapowers.html (last modified Oct. 24, 2000).

19. Assafa Endeshaw, Singapore Gets to Grips with the Internet, 7 J.L. \& INFO. SC1. 208, 219 n.40 (1996) (citing Republic of Singapore, Public Notice 2400, 38 GOV'T GAZEIIE EXTRAORDINARY No. 37 (1996)). The Singapore Broadcasting Authority replaced the public notice with a "schedule" version of the Code in November of 1997. See SINGAPORE BROAdCASTING AUTHORTTY, THE SCHEDULF INTERNET CODE OF PRACTICE (Nov. 1, 1997), at hitp:/www.sba.gov.sg/sba/ i_codenpractice.jsp. 
beyond control might be construed as permission to continue business as "normal" or "slightly less than normal.",

By adopting this "best endeavors" standard, Singapore acknowledges the impossibility of completely screening information flow over the Internet. The question is how significantly will Singapore's "Internet Code of Practice" impede information flow, that is, whether it will constitute anything more than a "speed bump on the information highway."

As a final dimension to the problem, the government's interest in participating in the global economy and using the Internet as a viable tool is counterbalanced by the government's desire to block information. The Chinese government faces this dilemma and has addressed the "volume problem" by restricting access:

This fact [i.e., the Internet is too large to monitor] is confirmed by the Chinese government's own efforts to limit access to a manageable number of users, which include limiting access to certain professions and keeping the cost of local Internet service artificially high. Such efforts are also counter productive, because to the extent they succeed and access to the Internet is limited, any economic development attributable to the Internet is correspondingly minimized. The government's other control mechanism, "firewall" software which blocks access to objectionable areas of the Internet, is similarly flawed .... The conflict is once again clear: to the extent that such outside contacts are numerous enough to spur economic development, they compromise the security of the network and prevent effective monitoring : . . . To prevent infiltration of its network by determined individual users, China would have to sever contact with the Internet completely. It remains to be seen whether the desire to retain social control would induce the Chinese government to take such a step.

20. Endeshaw, supra note 19, at 220-21. Dr. Endeshaw goes on to note, however, that in spite of the "best endeavors" proviso, other portions of the act create real obligations on the part of ISPs which cannot be interpreted as "business as usual." See id, at 221. See also Toh Han Shih, Set up Ne Industry Body to Oversee Practice Code: Panel, SINGAPORE NEWS, Mar: 1, 2000, at 11, available at, 2000 WL 4654099 . Singapore's Senior Minister, Lee Kuan Yow, has even urged China to let "the Internet generation regulate itself." Adam Creed, Let China's Internet Generation Rule ItselfSingapore's Lee, NEWSBYTES NEWS NETWORK, June 18, 2000, at 2000 WL 21178804.

21. Jeff Rose, Is Your PC a Speed Bump on the Information Highway?, SAN DIEGo UNIONTRIBUNE, Jan. 4, 1994, at 3, LEXIS, News Library, ALLNWS File (apparent first use of "speed bump" phrase in the media) (copy on file with author).

22. Delacourt, supra note 5, at 216-17 (citing Steven Mufson, China Opens a Window on Cyberspace; Growing Use of Internet Spreads Information, Once Banned ldeas, WASH. Post, June 19 1995, at A1, A15, available at 1995 WL 2099348: Internet Poses a Problem in Asia: Censorship More Difficult, S.F. CHRON. May 29, 1995, at A14, available at 1995 WL 5283648 ).

Despite government efforts to limit access, there were 56.6 million Internet users in China at the end of 2000. China is No. 2 in At-Home Net Access, WALL ST. J. Apr. 22, 2002, at. A14. That equates to roughly $4.4 \%$ of the population (number of Web users divided by population of $1,276.3$ million) See THE STATESMAN's YEARBOOK: THE POLTTICS, CULTURES AND ECONOMIES OF THE WORLD 2002
On November 7, 2000, China's Ministry of Information Industry issued regulations governing "information-release services." ${ }^{23}$ In addition to established firewall techniques, the regulations require ISPs to apply for permission to post news information with respect to preapproved, registered categories. ${ }^{24}$ The Chinese government prohibits Chinese Web sites from reporting news in general. ${ }^{25}$ In addition, ISPs must remove and report any prohibited material immediately, ${ }^{26}$ as well as keep records of IP addresses and domain names of "information disseminators."27 Prohibited information includes, among other things, information containing content "impairing the image and interests of the nation," "subverting state power," "undermining the state's policies on religion and advocating cults and feudal superstitions," and "disrupting social order and jeopardizing social stability .....28 In the past, China has been reluctant to crack down too harshly on its citizens for fear that "surfers might flee to Chinese-language sites overseas." Although the authorities now block many such sites, Chinese surfers are adept at using proxy servers to get around the firewall.",36

In essence, the question for restrictive governments is how to limit access to the Internet, while at the same time taking advantage of the Internet's economic benefits. Consequently, most governments may not be willing to completely sever access to the Internet, instead opting to find the proper balance between restricting access to the "undesirable" while using the Internet as a tool for development. ${ }^{31}$ Essentially, such

at 445 (Barry Turner ed., 2001). This compares to $32 \%$ of the American population that subscribes to an ISP at home. NATIONAL SCIENCE FOUNDATION, SCIENCF AND ENGINEERING INDICATORS, app. tbl. 8-31. at A-576 (2000). A separate study by NetValue.com indicated that the U.S. has roughly $50 \%$ of its households connected to the Internet, Singapore has $53 \%$ and China (but limited to the population centers of Beijing, Guangzhou and Shanghai) has $21 \%$. Press Release, NetValue. NetValue Releases First Figures on Asian Market (Sept. 4, 2000), at http:/www.netvalue.com corp/presse/cp0013.htm. Regardless of the wide range in estimations, the access of China's population to the Internet is severely restricted.

23. China Issues Regulations on Managing Internet Information-Release Services, CHINA ONLINE, Nov. 14, 2000, available at 2000 WL 4757832. (includes full text of regulations in English).

24. Id. at regulation arts. 6,11 .

25. See Ian Stokel, Chind Gov't. Issues Internet News Regulations, NEWSBYTES NEWS NETWORK, Nov. 7. 2000, at 2000 WL 27302427. See also China Sets up Bureau to Regulate Internet News: Mandate Concerns Private Web Site Owners, ToRonTo STAR, Apr. 22, 2000, at BU02, 2000 WL 19578102.

26. China Issues Regulations on Managing Internet Information-Release Services, supra note 23 at regulation art. 13 .

27. Id. at regulation arts. 14-15.

28. Id at regulation art, 9.

29. China Sets up Bureau to Regulate Internet News, supra note 25.

30. Id. Proxy servers are computers that may requests for a user operating on his or her own PC Only the proxy server knows the Internet address of the computer on which the user originates his or her request. Because the proxy server can launch a search or request, by using proxy servers, Internet users can often effectively disguise who they are.

31. The Internet is a factor in globalization and economic development. The general importance of globalization and economies of inclusion was noted in a recent report from the World Bank Although globalization has created problems, it has also been the engine of remarkable poverty reduction among 3 billion people of the new giobalizing countries." WORLD BANK, GLOBALIZATION GROWTH, AND POVERTY: BUIIDING AN INCLUSIVE WORID ECONOMY 146 (2002). China is 
authoritarian governments may suffer from the delusion of "having their cake and eating it too."

In summary, the ability of the Internet to route around blockages, the phenomenon of mirror sites, the sheer volume of the Net, and the desire of nations to take advantage of the Internet's potential as a tool for economic growth and delivery of vital scientific, economic and educational information render the Internet resistant to, and in some instances effectively immune from regulation.

\section{B. Arguments to the Contrary}

\section{Borders in Cyberspace}

In spite of the evidence suggesting the impossibility of regulating the Internet, some cyber law scholars are making arguments to the contrary. Chiefly, despite assertions otherwise, ${ }^{32}$ there are some recognizable borders in cyberspace, the existence of which implies the possibility of regulation.

The demarcation lines along network service providers such as America Online, CompuServe, EUNet, or Prodigy create important boundaries and the conditions of access for network connections. Private contractual arrangements determine the availability and the conditions of access for network conditions. These contractual arrangements define distinct borders between service providers. Participants on the GII [global information infrastructure] will be subject to different contractual rules, benefit from different resources, and adhere to different pricing plans according to network service agreements. In essence, the reach of a service provider's network establishes an important boundary line in an Information Society. ${ }^{.3}$

When coupled with the ability of states to impose criminal and civil liability upon ISPs operating within their borders, it is arguably possible to regulate the flow of information on the Internet. For instance, Felix

specifically noted in this report as having followed a path of globalization. Id. at 6 . At the same time, Internet influence and technology investment were also eredited with much of the economic growth. the rest of the world soon to follow." Michael J. Mandel \& Irene M. Kunnii, The Internet Economy: the rest of the world soon to follow. Michael J. Mandel \& Irene M. Kunnit, The Internet Economy:
The World's Next Growth Engine, Bus. WK. Oct. 4, 1999, at 72, available at http://www.businessweek. com/@@YYIrDYYOOh81010OA/archives/1999/63649004.arc.htm. The impact of the Internet on globalization has led many to wonder "whether countries that failed to make similar investments fin the Internet] would be left behind...." George R.G. Clarke, Development Research Group. World Bank, Bridging the Digital Divide; How Enterprise Ownership and Foreign Competition Affect Internet Access in Eastern Europe and Central Asia 1, available at http:/econ.worldbank.org/ files/2239_wps2629.pdf.

32. See, e.g, Johnson \& Post, supra note 7 and accompanying quote.

33. Joel Reidenberg, Governing Networks and Rule-Making in Cyberspace, in BORDERS IN CYBERSPACE 84, 88 (Brian Kahin \& Charles Nesson eds., 1997).
Somm, the managing director of CompuServe GmbH, CompuServe's German subsidiary, was convicted of complicity in distributing illegal pornography in violation of German law in $19988^{34}$ Apparently, the pornographic material forbidden under German law was accessible via CompuServe's network. After German law enforcement officials informed CompuServe GmbH in 1995 that its officers were able to access prohibited sites, the parent company, CompuServe, Inc., blocked access to some 200 electronic message boards for its four-million worldwide users. ${ }^{35}$ In February 1996, CompuServe eventually restored access to all but five of the message boards and provided software to its customers to filter unwanted material. ${ }^{36}$ Despite CompuServe's efforts. "Bavarian officials called the move an attempt to shift responsibility, ${ }^{, 37}$ and German officers found that they were again able to access prohibited materials. Consequently, Mr. Somm was charged in April $1997,{ }^{38}$ resulting in a conviction $^{39}$ that was eventually reversed on appeal. ${ }^{41}$

In a separate incident, German officials informed several ISPs that they faced possible liability for disseminating the works of Ernst Zuendel-a Toronto based neo-Nazi-and the Institute for Historical Review - a California based organization accused of publishing Holocaust denial tracts .... T-Online, a German service provider with nearly one million German subscribers, moved immediately to cut off access to the objectionable material, severing access to more than 1,500 unobjectionable sites in the process."

The response from the Internet community, however, was markedly different from the obscenity incident: America Online and Compuserve initially declined to comply. ${ }^{42}$ Furthermore, a grassroots effort by Internet users created multiple avenues of access around the blockage.

34. Cour Overturns CompuServe Germany Pornography Conviction, Dow Jones Int' News, Nov. 17. 1999, WL. EURONEWS, 11/17/99 DINS 10:21:00.

35. Peter Lotz, Internet Providers Beware, INT'L COM. LTTG., at 41, Feb, 1, 1999, available at 1999 WL 14253774. In 1995, German officials notified CompuServe of five offending news servers with postings for child pornography. Thereafter, the list was expanded to 182 newsgroups. Id. 36. Court Overturns CompuServe Germany Pornography Conviction, supra note 34. See also Johnson \& Post, supra note 7. at \&.

37. Court Overturns CompuServe Germany Pornography Conviction, supra note 34

38. Id.

39. See Lotz, supra note 35 (citing a Munich municipal court, case number 8340 Ds 465 Js $173158 / 95)$.

40. Court Overturns CompuServe Germany Pornography Conviction, supra note 34 over access by Neo-Nazis, ARIZ. REPUBLC, Feb. 3. 1996, at A19) 42. Delacourt, supra note 5, at 214. See also, America Online Running Afoul of Germans for File, Beyond Two Years; America Ontine May $F^{2}$, available at LFXIS, News Library, News Group Feb. 3, 1996, available at LEXIS. News Library, News Group File, Beyond Two Years: Bonn Approves Intermet Law Barring Pornography, Neo-Nazis, Deutsche Presse-Agentur, Dec. 11, 1996, available at LEXIS, News Library, News Group File. Beyond Two Years ("CompuServe GmbH, the German subsidiary of U.S. CompuServe Inc., last month said it was considering moving its administrative base 
[A]nti-censorship advocates at several United States universities engaged in efforts to thwart the restrictive actions of T-Online, including the creation of "mirror sites" in unrestricted areas of the Internet. These sites, which were essentially multiples of sites containing objectionable material, rendered T-Online's blocking efforts much less effective if not completely ineffective.

Perhaps the most important Internet case to date involved Yahoo! (the largest Internet portal in the United States, with 237 million users) ${ }^{44}$ and the online sale of Nazi memorabilia in violation of French law. The dispute resulted in litigation in both France and the United States, with courts in the two countries producing conflicting results.

The judge in the French case ordered a team of experts to find ways to block French users from accessing Yahoo's online auction site, due to the site containing Nazi memorabilia. ${ }^{46}$ Yahoo! experts testified that it was not possible to effectively filter access to its auction site. ${ }^{47}$

"It is a complete illusion to think you can seal off access to a site on a country basis," said Jean-Denis Gorin, technical director of a French Internet company, Edelweb, who has appeared as an expert witness for Yahoo!. "By identifying a surfer's country of origin, you can of course deny access to him, but there are many ways of getting round the ban," Gorin said. ${ }^{48}$

from Germany to another European country rather than comply with the law [German Internet legislation] it says would force a veil of censorship over a large part of the Internet.").

43. Delacourt, supra note 5, at 214. (citing Chris Cobb, Zundel a Winner in Internet Fight: Zundel Mirror Sites have Been Created at U.S. Universities, Defeating Efforts by Germany to Block Access to His Writings, VANCOUVER SUN, Feb. 3, 1996, at A3, Global NewsBank 008560D6D7EB22A AEFD95). For additional examples of how mirror sites can circumvent Internet censorship, see supra note 6 . 44. Yahoo! Media Relations, Yahoo! Financial Metrics, Q4 2001 Consumer and Usage Highlights, at http://docs,yahoo.com/info/pr/investor_metrics.html (last visited Oct. 31, 2002)

45. See UEJF et L.ICRA v. Yahoo!, Inc, et Yahoo France, T.G.I. Paris, Nov, 20, 2000, N" RG 00/05308, available at http://www.kentlaw.edu/perritt/conflicts/frenchorder.pdf (English trans. of Court Onder); Yahoo!. Inc, v. La Ligue Contre le Racisme et L'Antisemitesme, 169 F. Supp. 2d. 1181 (N.D. Cal. 2001) (motion to dismiss for lack of personal jurisdiction denied, 145 F. Supp. 2d. 1168 (N.D. Cal. $2001))$.

46. Angela Doland, French Court Orders Experts to Study Yahoo! Case, Associated Press Newswire, Aug. 10, 2000, WL, EURONEWS file, 8/10/00 APWIRES 21:12:00. The conclusions of the experts were published in a court order. See UEJF et LICRA v. Yahoo!, Inc. et Yahoo France, T.G.L. Paris, Nov, 20, 2000, $\mathrm{N}^{\circ} \mathrm{RG} 00 / 05308$, available at http://www.kentlaw.edu/perritt/ conflicts/frenchorder.pdf (English trans.). An estimated 30\% of French users cannot be identified by their IP addresses. Id. (reply of Laurie and Wallon).

47. Electronic Commerce: Liability of Research Tool Providers. EuR. ReP., at 470), Sep. 16, 2000 , 2000 WL 24318749.

48. Many Ways to Sidestep Geographical Filters on Websites, Say Experts, AgEnce FranCEPRESSE, Aug. 11, 2000, available at 2000 WL 24688577. Apparently, restricting Internet access based upon country, or even language, is not an effective solution.

Gorin says there are several ways of building such a firewall - but none meets the demanding criteria set down by the court.

The first is simply to filter out visitors on the basis of the country origin of their Internet Service Provider (ISP), whose address can be traced when they visit the site.

But this can easily be sidestepped if a surfer uses an ISP that is based in another country.

Subscribers to America Online's Internet access service, for instance, are routed through servers at the company's headquarters in Virginia, meaning that wherever they are in the world, they always appear to be in the United States.
At a subsequent hearing, the French court's own appointed experts testified that a "total prohibition would be impossible." The French court subsequently found that since Yahoo! was technically able to take measures to screen some French citizens from illegal sites, it was required to do so, and the court ordered Yahoo! to implement a "keyword-based filtering system" in ninety days or face fines of approximately $\$ 13,000$ per day. ${ }^{50}$ In November 2001, Yahoo! was victorious in a summary judgment action in the U.S. federal district court in San Jose, California, where the issue was the validity of the French order in the U.S. ${ }^{31}$ The District Court held, "the principal of comity is

The filter can also be thwarted by using one of the increasing numbers of websites which act as a relay station for surfers, providing them with total anonymity.

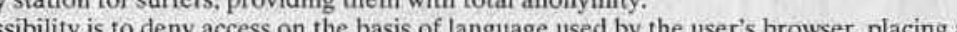
block, for instance in this case, on visitors who use French.

However, that would also penalise [sic] francophone users in Canada, Africa, Belgium and Switzerland, and in any case could be circumvented if the surfer converts the browser's language to English, which only requires the click of a button.

Betrand Velle, computer security consultant at French firm Apogee Communications, says ld

The Internet is a network whose design is not based on geography," he maintains. Id. One expert estimated that twenty-five percent of French Web surfers would circumvent any blocking efforts. Kevin J. Delany, Yahoo Tests Boundaries of Cyberspace Regulation, Wall St. J. EuR., Aug. 11, 2000, at 21, available at 2000 WL-WSJE 21068306

49. In French Yahoo Case, Experts Say Nazi Auction Ban Impossible to Enforce, AGENCE FrANCE-PRESSE, Nov, 6, 2000, available at 2000 WL 24753028.

According to their report, computer servers automatically register the nationality of 70 percent of French surfers when they log on. These users could easily be denied access to the sites.

But for the other 30 percent, effective screening would rely on their voluntarily submitting their nationality, a condition which could never be fully enforced.

The experts also considered that a monitoring mechanism for keywords that would trigger a cut-out [presumably, an automatic response or warning] when typed would also prove unworkable, because surfers would quickly find ways to circumvent it.

Id. See also Experts. Testify Before French Court Hearing Yahoo! Case, Dow Jones Int'l News, Nov. 6 2000, available at WL. EURONEWS file, 11/6/00 DIINS 15:04:00.

50. See Yahoo!, Inc. v. La Ligue Contre le Racisme et L'Antisemitesme, 169 F. Supp. 2d 1181 (N.D. Cal. 2001), motion to dismiss for lack of personal jurisdiction denied, 145 F. Supp. 2d. 1168 (N.D. Cal. 2001). See also Sylvia Dennis, French Court Orders Yahool to Screen Auction Site, NEwSBYTES NEWS NETwORK, Nov, 20, 2000, available at 2000 WL 27302966; John Tagliabue, French Judge Orders Yahoo to Block French Surfers' Access to Some Web Sites. NEW YORK TIMES NEWS SERVICE, Nov. 21. 2000, available at 2000 WL-NYT 0032600208; Mylene Mangalindan \& Kevin Delaney, Yahoo! Ordered to Bar French from Nazi Items, WALL ST. I. Nov, 21, 2000, at B1, available ar 2000 WL-WSJ 26617563. Apparently, the French court (the Tribunal de Grande Instance of Paris) is a lower court, and Yahoo! is studying whether or not it will appeal the ruling. See supra Dennis. See also Yahoo's Nazi Problem: The Long Arm of the Law, Time, Jan. 15, 2001, at 12, available at 2001 WL 5489144 and Clash of Cultures in a Borderless World, STATESMAN, Jan.14, 2001, at 2001 WL 4380940. In addition, the League Against Racism and Anti-Semitism and the French Union of Jewish Students have appealed the U.S district court decision. Matt Beer Appeal Filed on Yahoo French Nazi Memorabilia Case AGENCE FRANCE-PRESSE, Dec. 5, 2001, available at 2001 WL 25079521.

51. Yahoo!, Inc, v. La Ligue Contre le Racisme et L. Antisemitesme, 169 F. Supp. 2d 1168, 1186 (N.D. Cal. 2001) ("[A]t issue here is whether it is consistent with the Constitution and laws of the United States for another nation to regulate speech by a United States resident within the United States on the basis that such speech can be accessed by Internet users in that nation."). See also Yahoo! Fights French over Nazis, NEWSwIRE, Dec. 22, 2000, available at 2000 WL 7656130. "Greg Wrenn, associate general counsel international for Yahoo!, told US reporters that: 'what we're asking a judge to do is to look at the order from France and determine whether it is valid here in the U.S." Id. 
outweighed by the Court's obligation to uphold the First Amendment.", When filing the action, "Yahoo! attorney Gregg Wrenn said ... that Yahoo! would ignore the [French] ruling and refuse to pay the fines unless a U.S. court enforced it.", In addition to Yahoo!'s efforts, the European ISP Association has asked the European Commission to review the matter as a potential violation of EU law. ${ }^{\text {s4 }}$

Even prior to the ruling in the U.S. district court, ${ }^{55}$ some experts questioned whether the decision in the French court could be enforced since Yahoo! apparently operates, for the most part, outside France. ${ }^{66}$ One expert predicts, "companies are going to ensure that they have no assets in Europe to reduce the chances of being successfully sued."

The French court's decision, however, may have had some chilling effect. While Yahoo! cofounder and CEO, Jerry Yang, maintained prior to both the ruling of the U.S. federal district court and the French court's rulings that Yahoo! would not change content on its site. ${ }^{58}$ Yahoo! announced on January 3, 2001 that, "as a business decision," it would screen its auction site for Nazi items.

Nonetheless, even with Yahoo!'s cooperation, only an estimated seventy percent of French users can be screened. ${ }^{(6)}$ According to Yahoo!, the accuracy of the filtering technology is also estimated to be very low when measured by the rate of permissible sites needlessly screened out. ${ }^{61}$ As one columnist put it:

[I]dentifying French Web surfers isn't the toughest part. Yahoo also must rummage through trillions of bytes of data stored on its

52. Yahoo!, 169 F. Supp. $2 \mathrm{~d}$ at 1193.
53. Yahoo Secks to Block Order on Nazi Items. Net. French Judge Prohibited Sales to Its Citizens. Firm Says Court Does Not Have Jurisdiction, L.A. TIMEs, Dec. 25, 2000, at C5, available at 2000 WL

Firm Says

54. Ian Lynch, Ebusiness - ISPs Cry Foul Over Yahoo! Access Ban, CoMPUTiNG. Dec. 14, 2000, at 19, available at 2000 WL 8415745 .

55. Yahoo!, 169 F. Supp. 2 d at 1168

56. Dennis, supra note 50 ("[S]ince the bulk of its operations are outside of France, it is questionable whether the French courts could enforce their fines against the U.S. company.").

57. David Pringle. Some Worry French Ruling on Yahoo! Work to Deter Investments in Europe, WALL ST. J., Nov. 22, 2000, at B2, available at 2000 WL-WSJ 26617732.

58. Could the French Boycott Yahool, ZDNET NEWS, Jun. 20, 2000, 2000 WL 4020825. Apparently, Jerry Yang originally made the statement to the French newspaper, Liberation. Id. 59. Bearing the Standard, WALL. ST. J. EUROPE, Jan. 5. 2001, at 6. available at 2001 WL-WSJE 2839972. "Explaining what Yahoo! means by a 'business decision,' Sue Jackson of Yahool's London office says that the company had determined that most of its users would rather not have Nazi memorabilia and artifacts for sale by other users on the site." $1 d$.

60. See Mangalindan \& Delaney, supra note 50.

61. See id.

While it is technologically possible to block keywords such as "Nazi" on the Yahoo Web site, the accuracy of such a tool is less than $50 \%$. Yahoo! says, because it can't differentiate between the use of the word in hate material or literature such as "The Diary of Anne Frank.".... "Every time you mention Hitler in a memorial site for Holocaust survivors, it takes that site down," saic Greg Wrenn, Yahoo's associate general counsel for international affairs. "It's not appropriate to call that effective at all.

Id. Yahool's spokesman further stated that subjective judgment or human monitoring would be needed to determine the "context of the Nazi reference." $I d$. servers and identify all the references to Nazism. Then someone will have to create a separate index of the pro-Nazi materials, while allowing the anti-Nazi stuff to pass.

No indexing program yet devised can manage this,... just go to Yahoo and run a search under "Nazi." You'll see a link to U.S. government archives of Nazi documents, for use by scholars. ${ }^{62}$

Furthermore, existing services on the Web like Anonymizer and SafeWeb work to conceal user IP addresses which can be used to pinpoint user location. In addition, services like AOL do not use IP addresses but instead use separate networks. ${ }^{64}$ In sum. Yahoo!'s victory in the U.S. federal district court in San Jose ${ }^{65}$ opens the French court's order to legitimate questions regarding its effectiveness and enforceability.

In addition to independent attempts to regulate the Internet on a national basis, such as in Germany and France, the European Union has issued three Directives addressing the issue of liability of ISPs and the right of consumers to sue foreign suppliers of goods and services (where such goods and services have been supplied via the Internet). ${ }^{60}$ The threat of liability, whether for an ISP or other business enterprise, does have a potential chilling effect through industry and self-policing, including transactions involving dissemination and exchange of information. However, the EU Directives, to date, are limited in effect to commercial transactions and transactions involving businesses that collect personal information. Besides the EU Directives, France has adopted a Liberty of Communication Act, which requires Web publishers to register with the government. ${ }^{67}$

While this article has focused on barriers to information flow through legislation, regulation, and enforcement in the courts, there has been a recent significant case in Britain in which an ISP was found liable for a libelous message on a bulletin board it provides. Although the case did not involve parties from outside Britain, the international implications were noted: "So who cares what problems the Brits cause for their ISPs? We do, because under many standard analyses and the pending Hague Convention on Jurisdiction a wrongdoer can be sued where the effects of the tort are felt as long as he has reasonable business

62. Hiawatha Bray, Monsieur, Do You Yahoo?, Boston GLoBe, Nov, 30, 2000, at C1, available at 2000 WL 3353383.

63. $r d$.

64. Id

65. Yahoo!, Inc. v. La Ligue Contre le Racisme et L'Antisemitesme, 145 F. Supp. $2 d 1168$ (N.D Cal. 2001) (denying motion to dismiss for lack of personal jurisdiction)

66. Council Directive 2000/31, 178 O.J. (L 178) 1 (dealing with liability of ISPs, commercial communications, and electronic contracts): Commission Regulation (Final Proposal) 99/0348, 1996 O.J. (C 376E) 1 (dealing with enforcement of judgments), and Eur. Parl. \& Council Directive $95 / 46$. 1995 O.J. (L 281) $31-50$ (governing liability for transmitting personal information).

67. Ginger Adams Otis, Vive Le Censeur!, VIIL AGE VoICE, July 25, 2000, at 29, available at 2000 WL 8351912 . 
ties to the jurisdiction." ${ }^{68}$ Thus, the developments in case law cannot be ignored, particularly in light of potential developments with respect to the international enforcement of judgments.

\section{Government Filtering}

Perhaps the best case for the ability of authoritarian governments to regulate the Net has been made in a recent report, which specifically focuses on China and Cuba and was issued under the auspices of the Carnegie Endowment for International Peace. ${ }^{69}$ Its conclusion does not suggest that the Internet is a significant obstacle to totalitarian rule: "Taken together, the cases of China and Cuba should illustrate that the diffusion of the Internet does not necessarily spell the demise of authoritarian rule." ${ }^{70}$ Rather, authoritarian regimes for the present are "successfully controlling Internet use, even while using it to both extend their reach and push forward national development." successfully regulates potential challenges to government authority "through a combination of content filtering, monitoring, deterrence, and the promotion of self-censorship." Cuba, alternately, controls access, "including a prohibition of individual public access and careful selection of institutions that are allowed to connect to the Internet." ${ }^{73}$

Despite the Carnegie report's findings and conclusions, a careful reading of the report suggests that the "jury is still out" on the future of this issue.

Internet technology will continue to evolve over time, as will the myriad nontechnological factors that shape the environment in which Internet use takes place; as such, our observations act as snapshots of moving targets. Authoritarian regimes will have to continually adapt their measures of control if they want to counter effectively the challenges of future variations in information and communication technologies. It is quite possible that this task will prove too difficult and that use of ICTs [information and communication technologies] will eventually play a role in the democratic revolution that has been so widely predicted. ${ }^{74}$

The most significant parts of the report are those sections discussing Internet use in the "mass public." In China, many have predicted that its 68. John T. Aquino, British Court Concludes ISPs Liable for Bulletin Board Postings, LEGAL.
INTELLIGENCER, LEXIS, News Library, CURNWS File (quoting Stewart Baker of Steptoe \& Johnson in Washington D.C.).

69. SHANTHI KALATHIL \& TAYLOR C. BOAS, CARNEGIE ENDOWMENT FOR INTERNATIONAL Peace Global Policy Program, THe internet and State CONTROL IN Authoritarian REGIMES: CHINA. CUBA, AND THE COUNTERREVOLUTION 4 (July 2001) (Carnegie Endowmen Working Paper), available at http://www.ceip.org/files/pdf/21KalathilBoas.pdf.

$\begin{array}{ll}70 . & I d \text {. at } 17 . \\ 71 . & I d \text {. at } 2 . \\ 72 . & I d \text {. at } 15 . \\ 73 . & I d . \\ 74 . & I d \text {. at } 18 .\end{array}$ rising professional class will become "increasingly aware of foreign products, culture, and political norms." has been to filter and block Internet materials and promote selfcensorship. In chat rooms, censors routinely remove offensive comments. Crackdowns encourage business owners to "self-police." Yet, the Carnegie report's analysis misses the fundamental issue: how effective can filtering be? While the report notes that China's response to the potential political impact of the Internet on the mass public is chiefly through "filtering material and promoting self-censorship," the report does not, and indeed perhaps cannot, give any insight into how effective those efforts are. While there is general discussion of "Big Mama" - chat room administrators who screen subversive comments, shutting down sites within China, and blocking of foreign sites with respect to the Falun Gong reform movement - there is no attempt to study how effective these techniques are or what kinds and amount of information is getting through. The report only discusses the response of the Chinese government, not its effect on information flow. Although primarily a question for information scientists and sociologists, the real question remains: what do Chinese citizens have access to as a result of the Internet, and how is this different from what they had access to before the Internet? Without better information and systematic study of Internet user behavior in China, any conclusions as to the impact of the Internet in China are premature.

What is known about China's attempt to regulate the Internet is that it has attempted to regulate the Net using filtering and self-policing. The first problem with filtering and censorship of the Net is scale.

"Security agencies [in China] are spending millions of dollars to buy the latest technologies, but how can they keep track of volumes like that?" asked Sin Chung-kai, a member of Hong Kong's Legislative Council who represents the territory's information- technology industrial sector. When the number of users goes over 100 million, the political environment will change."

Approximately 56.6 million Chinese have access to the Internet (or $5.5 \%$ of the households in China). ${ }^{78}$ More importantly, there are significant technological limitations as to the effectiveness of filtering. For instance, a study of the efficacy of four different commercial software filter products revealed that only when all four products were combined, they collectively blocked objectionable materials $25 \%$ of the

75. Id, at 6 .

76. Id.

77. Tyler Marshall \& Anthony Kuhn, As Online Users Grow Exponentially, Beijing Fights to Keep Cyberspace an Apolitical Playground, L.A. TiMES, Jan. 22, 2001, at A1, available at LEXIS, Nexis Library, News Group File (suggesting the scale of Internet usage in China does not foretell the fall of China's communist party, but a more gradual change). See also supra text accompanying note 22.

78. China is No. 2 in At-Home Net Access, supra note 22. 
time and that they blocked unobjectionable material $21.3 \%$ of the time." Assuming that the Chinese government found $1 \%$ of the eight petabytes $\left(8 \times 10^{15}\right.$ bytes) available through the Web to be objectionable, or 10 terabytes ( $10^{13}$ bytes), then using current filtering technology, 2.5 terabytes of objectionable material would escape filtration (which is roughly the amount of information stored in an academic research library).

Like filtering software, Internet surveillance systems are subject to technical boundaries. The technical limitations of the FBI's Carnivore digital surveillance system are indicative of the inherent limitations with wide-scale Web monitoring. ${ }^{81}$ Even without conjecture on the previous statement, which was based upon the under- and over-inclusion rates of various commercial filtering systems, there is significant evidence of information leakage. The Washington Post reported that while its website was blocked, the website of the International Herald Tribune (a paper with which it had a joint venture) and MSNBC.com were not. Nor were the South China Morning Post (a Hong Kong paper), New York Times, nor the Wall Street Journal. ${ }^{\times 3}$ It is also noteworthy that a significant number of Chinese Web surfers $-25 \%$ of adult users, and $40 \%$ of those under eighteen - spend time at foreign sites. ${ }^{84}$ Although eventually blocked by Chinese authorities, one anonymous proxy server (focusing on Chinese Web surfers) had an estimated 2.5 million page views per day within five months of being launched. ${ }^{85}$

Even if the Chinese government develops superior filtration systems, the scale of the Internet and the inherent technical limitations in filter systems (whatever methods they use-key word detection, site blocking, or rating systems) still permit significant information flow over the Internet. Furthermore, advances in technology not only help government censors, but also improve the ability of Web surfers to

79. Christopher D. Hunter, Internet Filter Effectiveness-Testing Over-and Underinclusive

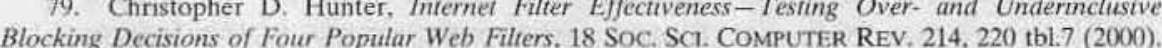
Blocking Decisions of Four Poputar Web Filters, 18 SOC. SCI. COMPUTER REV. 214,220 tbi.7 (2000).
The percentage of objectionable sites not blocked by each product varied from $83.3 \%$ to $30.6 \%$. Sce The percentage of ob

80. Lyman et al. How Much Information?, at http://www.sims.berkeley.edu/research/ projects/how-much-info/datapowers.html (last modified Oct. 24, 2000)

1. See IIT RESEARCH INSTITUTE, supra note 16.

82. Clay Chandler, China Again Censoring Web: After Summit, Blocking of Foreign Sites Resumes, WASH. POST, Oct. 23, 2001, available at LEXIS, News Library, News Group File. Most Recent Two Years.

83. Id. The Wall Street Journal was effectively off limits to Chinese users because of subscription fees. $/$.

84. Robert Marquand, China Tames the Wild, Wild Web, Christian SCl. Monitor, Aug. 2, 2001, at 10 (reporting that China effectively regulates the Internet through self-policing).

85. Chinese Government Attempts to Block Access to SafeWeb; Silicon Valley Startup Answer with Triangle Boy Technology in Effort to Combat Internet Censorship, BUs. WIRE, Mar. 13, 2001 available at LEXIS, News Library. News Group File, Most Recent Two Years. Safo Web confronted the blockage by China by releasing free proxy software that volunteer Web sites could download to function as proxy cites, hopefully circumventing Chinese censors by sheer number. Sec infra notes 86 . 87 and accompanying text circumvent censorship blocks and surf with anonymity. ${ }^{86}$ For instance, SafeWeb (now in concert with the Voice of America) has released free peer-to-peer proxy software called Triangle Boy, specifically designed to thwart Internet censorship such as in China.

Volunteers can turn their PCs into "packet reflectors," or proxies, for SafeWeb by installing the Triangle Boy application. Since the Chinese government is unlikely to block access to the volunteer PCs, they can act as encrypted gateways to the Internet and allow Chinese citizens full access to an uncensored Web.

The potential implications of thousands of Web servers (essentially any computer with a dedicated line) functioning as proxies to "anonymize" and encrypt Web traffic are profound-perhaps as significant as the initial design of the Web to be dependent upon logical and not physical addresses and to provide multiple routes for information transfer. One can imagine Western universities, libraries, governments, non-profits, and a host of expatriates actively promoting participation in vast networks to provide anonymous and uninterrupted access to information over the Web.

The alternative for an authoritarian regime is to cut access to everything but approved sites; however, countries like China have resisted this because of the need for the economic benefits. "The great enemy of those [in China] seeking to control the Internet is its growthgrowth fueled largely by the recognition among China's reformers that they have no choice but to embrace the Internet if they are to compete in the global marketplace." ${ }^{188}$ Similarly, there may be real economic tradeoffs for restricting access to a national intranet, also under discussion but repeatedly delayed. ${ }^{59}$ "To capitalize on economic potential of a booming information sector and technologically savvy workforce, China needs to promote widespread Internet access while maintaining control through other means." "x) Less restricted access means greater potential for economic development, while more restricted access may be easier to control but less profitable."

86. See TriangleBoy: Privacy and Security at http://www.safeweb.com/tboy_service.html (las modified May 9, 2002). An alternative to TriangleBoy, known as Peekabooty, was introduced at the CodeCon 2002 conference. Pratap Ravindran, A Peek into the Forbidden, BUS. WIRE, Mar. 6, 2002, available at LEXIS, News Library, News Group File, Most Recent Two years. Besides providing fo volunteer proxy servers, Peekabooty encrypts its traffic to look like credit card information. Id. See also Peekabooty, at http://www.peek-a-booty.org/pbhtml/index.php (last visited Oct. 31, 2002).

87. Chinese Government Attempts to Block Access to SafeWeb, supra note 85.

88. See Marshall \& Khun, supra note 77.

89. KALATHIL \& BOAS, supra note 69 , at 9 .

90. Id, at $15-16$

91. Cuba's policy of severely limiting Internet access is likewise subject to the same tradeoffs Id. at 13 ("iilnternet could present another lucrative opportunity for Cubans to make money"). Fo additional discussion, see supra notes $22-31$ and accompanying text. 


\section{Technological and Regulatory Response to Demands of Business and} Commerce

Even if current technologies do not allow regulation of the Net, Professor Lawrence Lessig argues that as the Internet responds to the needs of business and commerce by changing its architecture and through the use of certificates of authentication, ${ }^{, 2}$ such changes will also enable governments to effectively establish jurisdictions or "zones" of regulation on the Internet. ${ }^{93}$ While it is possible for users to select among such zones, referred to as "exit" power or "voting with one's feet" thus resulting in a competition between zones of rules in cyberspace for users - there are costs in doing so.

Professor Lessig also argues that the balance between "open source" and "closed source" Internet applications and protocols directly affects the ability of government to regulate the Net. For example,

[a]lthough Netscape [open-source code] could offer a feature that the French government wants [demands], there is no reason to believe that users would want this same feature. Another supplier would undoubtedly provide an SSL module [Netscape's opensource protocol for exchanging encrypted information between a

92. LAWRENCE LESSIG, CODE AND OTHER LAWS OF CYBERSPACE 208 (1999) ("Commerce, 1 argued [in part 1], will push for a certificate architecture that would enable its own form of control That architecture would enable some forms of state control. But the precise control would depend on the architecture.")

93. Id. at 207. Professor Lawrence Lessig argues:

93. Id. at 207. Professor Lawrence Lessig argues:
A certificate-rich Internet, for example, would enable sovereigns to reclaim some of their A certificate-rich Internet, for example, would enable sovereigns to reclaim some of their authority. In

rules.... A world where certificates were generally available would be a world where states could again insist that their rules be applied, not the rules of the dominant nation (the United States) or the Net.

Id. Lessig assumes that certificates will permit identification on some political-geographical basis, a necessary requirement for sovereign jurisdiction and enforcement. Whether the evolution of the Web necessary requirement for sovercign juris do be seen of the Web to meet he needs of comerce certainly, Swizerland's historical baking laws, which placed a prenon commerce can bo conduct secircly wirh Internet zone, wholly inmune from sovereign law, is not too tar-letched. Apparently, a group of investors is working to establish an internet hub on a WWil gunnery platform in the North Sea, the owner of which claims independent sovereignty as the "Principality of Sealand." See Simson Garfinkel, Welcome to Sealand. Now Bugger Off, WIRED, Jul. 2000, at 230.

94. See Lessig, supra note 92, at 201. Professor Lessig sets forth the arguments of David Post and David Johnson, which emphasizes the choice of users among cyberspace domain "rule-sets." "Individuals will choose to enter one rule-set or another. As rule-sets compete for our attention, the world of cyberspace will come to be defined by this competition." It. (citing David G. Post, Anarchy, State, and the Internet: An Essay on Law-Making in Cyberspace, 1995 J. ONLINE L. art. 3, q (visited Nov, 28, 2000), at http://www.wm.edu/law/publications/jol/post.html).

95. Professor Lessig explains

In cyberspace no assets are transferable. You can move from one community to another, but with each move you must start over again.

Paradoxically, then, we might say that it is harder to change communities in cyberspace than it is in real space. It is harder because you must give up everything in a move from one cyber-community to another, whereas in real space you bring much of it with you.

See LESsig, supra note 92 , at 202 browser and a server] without the alteration demanded by the French government.

The point is simple, but its implication profound. To the extent that code is open code, the power of government is constrained. Government can demand, can threaten, but when the target of its regulation is plastic, it cannot rely on its target remaining what it wants.

Because open-source code can be freely copied and modified, it does little good for governments to pressure industries to accommodate state interests. A particular service can be easily co-opted and modified by a competitor who uses open source code and who might not be so sensitive to government pressure.

The next point in Professor Lessig's argument is that the balance between "open" and "closed" code is not fixed, and needs to be monitored. ${ }^{97}$ In essence, a shift to closed code ought to enhance government power to regulate. ${ }^{98}$ It also bolsters the power of business to stifle competition and even control content. ${ }^{99}$ Consequently, a shift to closed code favors government regulatory power, and an industry movement in that direction would suggest, per Lessig's argument, that much more rigid Internet regulation would become possible. It should be noted, however, that other factors besides the balance of closed and open code may influence whether a particular service or product can be easily co-opted by competitors, who may be beyond the reach of government regulators. For instance, competitors of Yahoo! in France may offer Web services to customers that are non-IP-based, which would allow geographically indistinct or anonymous browsing ${ }^{100}$ and thereby diminish Yahoo!'s French market share and indirectly undermine the efficacy of a French court's order which compelled Yahoo! to ban French users from sites selling Nazi materials. ${ }^{101}$ Consequently, the balance and trends of closed versus open code does not solely determine government ability to regulate Internet information flow.

New technologies not only enable government regulatory muscle, ${ }^{102}$ they elicit regulation as to the demands of business and industry which cause them to affect information flow over the Internet, sometimes in an unforeseen manner. For instance, in an essay introducing his newest

96. Id. at 106-07.

97. Id. at 104 ("It is this balance that we need to track-the balance between open and closed code on the Net. Most of the application space that ordinary users now use is closed.")

98. Id. at 100, 107 ("[T] the extent that code becomes open, government's power is reduced."). 99. See Lawrence Lessig. The Internet Under Siege, ForEIGN POL'Y, Nov.-Dec. 2001, at 56, 64 [hereinafter The Internet Under Siege].

100. For example, America Online's customers are all routed through Virginia. See supra note 48.

101. See supra note 46 and accompanying text.

102. For an example of how new technologies may diminish government regulatory ability over the Internet, see supra notes 86-87 and accompanying text. 
book, ${ }^{103}$ Lessig gives an example of how the Digital Millennium Copyright Act (DMCA) has been used to limit information flow. ${ }^{104}$ In August of 2001, EnviroLink Network discontinued the website of Stop Huntingdon Animal Cruelty (SHAC). ${ }^{105}$ Nonetheless, SHAC has continued to operate two other sites-www.shac.net and www.shacusa.net-and publish company name lists. ${ }^{106}$ The SHACUSA site (www.shacusa.net) currently appears to be hosted on the "stellar.htirust.net" and "sealand.ethicalhost.net" name servers, which are registered to TUCOWS, INC. in Ontario, Canada. A MSDOS "tracert" commercial search reveals both of these servers to be in the Netherlands. Similarly, the international SHAC site (www.shac.net) is hosted on Dutch servers. ${ }^{107}$ Consequently, Lessig's example may actually demonstrate the ubiquitous nature of web sites and limited practical effect that private lawsuits, including claims made under the DMCA, can have on expression via the Internet.

The ease of moving and obtaining Web servers (such as illustrated by unsuccessful attempts to regulate SHAC), the transferability, plasticity and ubiquity of open-source code, and the realities of anonymous and geographically indistinct Web surfing substantiate the axiom that "the Internet interprets censorship as damage and routes around it." ${ }^{\text {"as }}$ Not surprisingly and quite sensibly, even Singapore, with its relatively aggressive standards for regulating ISPs, acknowledges the futility of completely regulating the Net:

To fully control what goes on in the Internet is not possible and it is not our intention to do so. We will therefore adopt a pragmatic approach in formulating our regulatory framework; one which regulates by exception, ensures minimum standards are kept and encourages responsible use of the Internet .... [W] strongly encourage community policing as a long-term solution for the healthy development of the Internet. ${ }^{109}$
The question, however, has never been one of total government control or total freedom to surf without restrictions, but whether the Internet has the potential to affect profound change even in the most restrictive government regimes. ${ }^{110}$

\section{Summary}

In light of the incidents in Germany and France, the theoretical arguments made by Professor Lessig, and in consideration of the imperfect policies of Singapore and China, the presence of effective regulatory borders in cyberspace is subject to doubt and raises the question: what are the consequences for governments and states if the Internet cannot be regulated, or only partially regulated?

\section{MARKET FOR LOYALTIES THEORY}

In a series of articles and books, "II Monroe E. Price, a professor of law at Cardozo School of Law, ${ }^{112}$ has argued that the behavior of states in regulating transborder information flow, particularly international broadcasting, can be explained by what he terms "the market for loyalties." "13 This market, although different from the market for goods

110. There is evidence that the Internet is fundamentally affecting China despite its attempts to

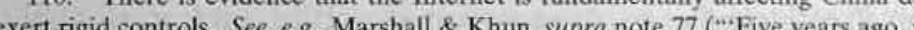

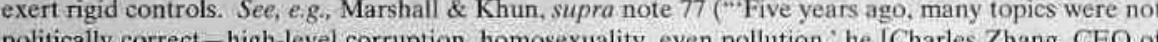
potitically correct-high-level corruption, homosexuality, even pollution, Seeking largest Internet portal] said, 'People's tolerance for these topics has increased. ": Analysis. Seeking Truth from Facts - China's Changing Medil Scene, BBC Media, Feb. 22, 2001, available at LEXIS. News Library. News Group File, Most Recent Two Years ("An estimated 330 Chinese language newspapers are available online .... In terms of access to information, China today is less secretive than at any time since 1949."); and Marquand, supra note 84 ("Some 300 [Chinese] cities now have high-speed access to the data pipeline. China users here can log on to Taiwan daily newspapers; and within reason, they can exchange skeptical messages about news events.").

111. Monroe E. Price, The Market for Loyalties and the Uses of Comparative Media Law, in Broadcasting ReForm in India: Media LaW from a Global. PERspeCtive 93 (1998 [hereinafter Comparative Media Law]; Monroe E. Price, TElevision: THE PUBLIC SPHERE AND NATIONAL IDENTITY (1995) [hereinafter TElevision]; Monroe E. Price, Law, Force and the Russian Media, 13 CARDOZO ARTS \& ENT. L.J. 795 (1995) [hereinafter Russian Media]; Monroe E. Price. The Market for Loyalties: Electronic Media and the Global Competition for Allegiances, 104 YALE L.J. 667 (1994) [hereinafter Market for Loyalties].

112. See supra note 2.

113. Interestingly, a similar phrase, "the market for eyeballs," has been used by scholars in connection with the Telecommunications Act of 1996. "Market for eyeballs" first appeared in print in an article by Thomas G. Krattenmaker. The Telecommunications Act of 1996, 29 CONN. L. REV, 123 168 n.218 (1996), reprinted in 49 FED. COMM. L.J. 1, 45 n.214 (1996). Eben Moglen coined it for regular usage at a Columbia University symposium. Eben Moglen. Telecommunicutions Unscrambling The Signals, Unbundling The Law: Article: The Invisible Barbecue, 97 COLUM. L. REV. 945, 952-53 (1997), available at hitpil/emoglen: Article: The Invisiole Barbecte, 97 CoLUM. L. REV 945, $952-53$ (1997), available at http://emoglen.law.columbia.edu/publications/barbecue, html. Since then, the term has been used in a half-dozen articles. See Cass R. Sunstein, Television and the Public Interest, 88 CAL. L. REV. 499, 514 (2000); Yochai Benkler, VIACOM-CBS Merger: From Consumers To Users: Shifting The Deeper Structures Of Regulation Toward Sustainable Commons And User Access, 52 FED. COMM. L.J. 561,562 (2000): Scott Killingsworth, Minding Your Own Business: Privacy Songs And Amish Children: Autonomy, Information, And Law, 76 N.Y.U.L. REV. 23, 88 (2001); and 
and the "market of ideas," can be described as the exchange of "identity" (supplied by governments and traditional power structures) for loyalty from their constituents and subjects. This "market for loyalties" adheres to economic concepts such as buyers and sellers, currency, monopoly, regulation, competition, and supply and demand.

\section{A. Summary of Professor Price's Application of Economic Theory}

Professor Price has proposed application of an economic theory, known as the "market for loyalties," to explain the monopolistic and oligopolistic behavior of states and their power holders have in trading national identity for loyalty. Competing identities (identities sponsored by someone other than the state and its constituent power elites) are provided both by groups seeking power (whether entirely within national boundaries or transcending them), and by Western commercial culture. ${ }^{11}$ Because these competing identities weaken the value of the national identity, ${ }^{115}$ which governments trade for the loyalty of their citizens, governments often work to restrict the entrance of competitors into the loyalty market. Besides direct censorship, government restrictions in the broadcast media include suppressing broadcasting from beyond national borders, maintaining a national broadcasting monopoly, restricting the number and licensing of frequencies, and imposing frequent licensing renewal requirements. ${ }^{116}$ An additional characteristic of media regulation is that it reflects the existing power structure, and predictably, it is only changed if it fails to protect the existing power structure's marketing of identity or if the power structure shifts to different parties.

\section{B. Elements of the Market}

This section will set forth the elements of the "market for loyalties"-sellers, buyers, products, and currencies of exchange-and will look more closely at the parties and values playing the various economic roles in the market.

According to Professor Price, governments regulate information flow because they are competing for loyalty or allegiance in a market. ${ }^{11}$ The terms "government" and "state" are actually inadequate to describe

Patrick Maroney, Internet: The Wrong Tool for the Right Job: Are Conmercial Websites Places of Public Accommodation Under the Americans with Disabilities Act of 1990?. 2 VAND. J. ENT. L. \& PRAC. 191, 193 (2000). Despite the "market for eyeballs" being in vogue, the author prefers the term "market for loyalties." While "market for eyeballs" conveys the sense of advertising to attract an audience, the "market for loyalties," as explained by Professor Price, captures the essence of the "identity" for "loyalty" exchange. Furthermore, "loyalty" suggests more than passive "brand recognition" rather than active commitment to something.

114. See infra Subsection D.

Id.

116. See infra notes $129-132$ and accompanying text.

60. the regulators of information in the market. In applying his market analogy to radio, cable and satellite broadcasting regulation, Professor Price describes a broader concept, identifying those who play the roles of sellers in the marketplace:

[T]he supply side[, the seller,] in the market for loyalties has a structure that is badly served by reductionist terms like 'state,' or 'government,' or political party. The sellers in this market are all those for whom myths and dreams and history can somehow be converted into power and wealth-classically states, governments, interest groups, business and others. ${ }^{118}$

In other words, sellers in the "market for loyalties" are those parties with a message that can be traded for loyal followers and power. That message can consist of a party platform, ideology, or national ideals and aspirations. It may be as ephemeral as the hope for a better future or as concrete as the desire for a national homeland. Identity is valuable to buyers as it contains both the legacy of their past history and the promise of their dreams for the future (whether it is for wealth, a better life, or an education). For example, "[r]adio became instrumental [to the state] as a forum for explanation, for patriotism, for mobilization, and for maintaining morale in the Second World War." ${ }^{119}$ The buyers in this market are citizens and the currency in this market is loyalty.

The "buyers" are citizens, subjects, nationals, consumersrecipients of the packages of information, propaganda, advertisements, drama, and news propounded by the media. The consumer "pays" for one set of identities or another in several ways that, together, we call "loyalty" or "citizenship." Payment, however, is not expressed in the ordinary coin of the realm: It includes not only compliance with tax obligations, but also obedience to laws, readiness to fight in armed services, or even continued residence within the country. The buyer also pays with his or her own sense of identity.

Although in Professor Price's "market for loyalties," it is identity that is purchased by citizens, he notes that the exchange rate for loyalty (or cost to the seller) can be quite high, as in the instance of draft compliance and historical incidents of mass desertion. ${ }^{121}$ In such circumstances, the price

118. Market for Loyalties, supra note 111 , at 669 . This paper will use the broader notion advocated by Professor Price when referring to "states" and "governments."

119. TELEVISION, supra note 111 , at 7 .

120. Market for Loyalties, supra note 111, at 669-70 (citing GEORGE P. FLETCHER, LOYALTY: AN ESSAY ON THE MORALITY OF RELATIONSHIPS (1993); Albert O. Hirschman. EXIT, VOICE, AND LOYALTY (1970): Mark Kelman, Consumption Theory, Production Theory, and ldeology in the Coase Theorem, 52 S. CAL. L. REV. $669(1979))$.

121. Market for Loyalties, supra note 111 , at 670

Compliance with the draft is not a perfect sign of a community's loyalty to its government because of a history of exemptions, deferrals, inequities, and, ultimately, the end of conscription. But studies of compliance, desertion, or the burdens of raising an army through means other than conscription suggest that the cost of loyaity is sometimes quite high. History is studded with cases where mass desertion has meant the end of an empire; where all of a sudden, the duty to fight for a particular cause can no longer be enforced. $I d$. 
of loyalty is measured by the cost of an alternative and its consequences (the risk of desertion, the effect of mass desertion on the state). A simple representation of the elements of the "market for loyalties" may be presented as follows:

\begin{tabular}{|l|l|}
\hline Economic Term & Market for Loyalties \\
\hline Sellers & Governments \\
\hline Buyers & Citizens \\
\hline Price/Currency & Loyalty \\
\hline Goods & Identity \\
\hline
\end{tabular}

Professor Price describes all of the elements of a classic marketbuyers, sellers, products, currency, exchange and price (as determined by the value of the alternative)-and equates those elements with the constituent elements of the relationship between a sovereign and its subjects. A more thorough understanding of Professor Price's "market for loyalties," however, requires an examination of the dynamics of the market's exchange - the bartering of identity for loyalty.

\section{Identity and the Competition for Loyalty}

The preoccupation of many authoritarian governments with the regulation of advertising, particularly Western advertising, illustrates the relationship of identity and the competition for loyalty. Even the advertising of commercial goods can threaten market identity.

The preoccupation that governments have long had with limiting advertising messages and excluding competition from commercial broadcasters suggests that the impact of programming on public allegiances yields a substitute for more traditional packages of identity .... In this sense, marketers of pure national identities, and ideologies that parade as such, compete with sellers of consumer goods who are trying to impress the citizen with another identity. Here the question is how a person, certainly one in a developed society, decides, at the margin, whether a higher or lower percentage of disposable income should go to the state (in taxes), say for education or environmental protection (to be generous), or, instead, for personal goods like food or television sets or automobiles.

Underlying the commercial message of Western culture is a theme that threatens the purveyors of national identity-the message of individual

122. Comparative Media Law, supra note 111, at 452. Quite correctly, Professor Price briefly otes that the contest for loyalty involves the economic concept of elasticity of demand. $I d$. at n. 19 . Elasticity is discussed in much greater detail below. See infra notes 139, 153-155 and accompanying text. choice. ${ }^{127}$ Ultimately, states and their constituent governing powers are concerned about the potential for the marketing of competing identities to destabilize the existing status quo.

\section{Destabilizing Influences-Competing Groups and Western Commercial Culture}

There are two distinct destabilizing influences, perceived or real, which evoke a reaction from authoritarian states: (1) threats to national identity from ethnic communities, religious groups, or sectors of society from within the state, or which transcend traditional national boundaries; and (2) Western commercial culture.

\section{Competing Internal Groups}

Not all competitive identities originate abroad or can be characterized as "foreign influences." For example, the secular government of Turkey has been challenged by domestic Islamic groups and has responded in both an offensive and defensive mode with the media:

Since the rise of Kemal Ataturk, the Turkish government has considered Islamic sects, groups now labeled "fundamentalists," a threat to the secular state and has sought to limit the use of mass media by these religious competitors. Turkish Radio and Television Authority (TRT) has not only been monopolistic, "it [has] also essentially [been] the voice of the state, disseminating the unitary ideology and culture of Turkish republicanism and [sic] highly susceptible to government intervention." ${ }^{12}$

Fundamentalist Islamic broadcasts, even if originating within Turkey, are perceived as a threat by Turkey's secular government. It is not surprising that the government of Turkey has maintained tight control over its media, both to disseminate its own views and to keep its opponents, many of whom are of domestic origin, from voicing their own messages.

123. Professor Price explains:

We see assertions of national identity in the interstices of commercials, in their depiction of idealized home life, opportunities to travel, or certain idea of traditional family values. Arguably, one message of the sellers of toothpaste and automobiles is the claim that the opportunity to have maximum choice to consume is good.

Comparative Media Law, supra note 111 , at 453.

124. Market for Loyalties, supra note 111, at 673 (quoting Asu Aksoy \& Kevin Robins, Gecekondu-Style Broadcasting in Turkey: A Confrontation of Cultural Values, INTERMEDIA, June-July 1993, at 15 and ELI NOAM, TELEVISION IN EUROPE 251 (1991) respectively). "Charged by statute with promoting the values of the country, unity, republic, public order, harmony, and welfare and [strengthening] the principles of Kemal Ataturk's reforms,' TRT has been an instrument for cohesiveness' in an environment in which there have been deep divisions about alternative national identities." Id. (quoting Aksoy \& Robins, supra). 


\section{Effect of Western Commercial Broadcasting and Culture}

Competing identities, identities other than those supplied by the State and the existing power structure, originate not only from indigenous groups within a particular country, but from foreign sources as well. The effect of foreign commercial speech can destabilize, or be perceived as destabilizing, totalitarian and third world governments and potentially the democratic institutions of the primary and secondary world powers. Destabilization results if there is a sudden decrease in price (loyalty) exchanged for the identity supplied by the State and traditional power holders. In fact, Western advertising (a form of competing identity) has been credited with contributing to the demise of communism in Eastern Europe.

The most avid proponents of free market television have, consistent with this position, argued that the images of Western society, including its advertising, are entitled to some of the credit for the fall of the Berlin Wall and the collapse of the Soviet Union. The point here, of course, is not the truth of the claims about the impact of messages, but the perception of that impact and the rhetorical use of it in rendering markets more open or closed. ${ }^{125}$

The threat of Western broadcasting has been acknowledged by the Chinese government. In a statement from China's Ministry of Radio, Film, and Television, such broadcasting is expressly recognized as detrimental to China's national values and sense of identity:

International satellite dissemination conducted by Western developed countries threatens the independence and identity of China's national culture. We should seriously deal with this situation. These [cultural] factors include loving the motherland, hard work, advocating industry and thrift, ... taking a keen interest in science, attaching importance to culture, ... and stressing moral courage. The national spirit contains patriotism, collectivism, hard work [sic] and bravery, defying brutal force and daring to fight ...

125. Comparative Media Law, supra note 111, at 453-54 (citing SUBCOMM. ON INT'L OPERATIONS, HOUSE OF REPRESENTATIVES, 102D CONG., REPORT OF THE PRESIDENT'S TASK FORCE ON U.S. GOVERNMENT INTERNATIONAL BROADCASTING (Comm. Print 1992)). Ironically, some argue that the forces of Western broadcasting, including commercials, now threaten the emerging democracies in the former Soviet states:

Many of the panelists were concerned that filling the foreign public space with Wheel of Fortune and the throbbing and distracting siren songs of MTV might subvert or inhibit the building of democratic practices. The job of being a citizen in a transitional society would be tough and grueling [sic], demanding full attention to the structure of government and society. An overly zealous commercial culture,

TELEVISION, supra note 111, at 22 (referring to a panel discussion at a conference of the American TELEVISION, supra note 111, at 22 (referring to a panel discussion at a conference of the American Enterprise Institute for Public Policy Research, The New Global Popular Culture: Is it American? Is it Good for America? Is it Good for the World?, (Mar. 10-11, 1992), Washington. D.C. (organized by Ben Wattenberg, Senior Fellow)). The concern is whether the diminution of loyalty to traditional government authority as a result of Western media ultimately makes the establishment of new
Precisely because of this, we take seriously the infringement of overseas radio and television and the influence they bring which hampers the national spirit to expand. ${ }^{126}$

Given the role (whether perceived or actual) of Western commercial culture in destabilizing the former Soviet Union and the former communist states of Eastern Europe, China's concern cannot be dismissed as mere paranoia, but rather it represents an astute awareness of the classic divide between the values espoused by the communist state and those portrayed and promulgated by the Western media. ${ }^{127}$

\section{E. Regulation to Preserve Monopoly (or Oligopoly) of Identity}

To protect their market share, and also to reduce the price of loyalty (or correspondingly to increase the value of national identity), governments, states and the existing power structures attempt to limit competition in the market.

In this market, large-scale competitors for power, in a shuffle for allegiances, use media regulation to organize a cartel among themselves. Regulatory arrangements reflect a competition not only for goods, but also for minds and souls. The State seeks 126. Zhao Shuifu, Foreign Dominance of Chinese Broadcasting -Will Hearts and Minds Follow?,
INTERMEDIA, Apr-May 1994, at 8-9, quoted in Market for Loyalties, supra note 111, at 676, n.42. China does not, however, advocate completely isolating itself from Western culture. Rather, paternalistic control over foreign influences is advocated in order to "distinguish between good and bad." Id. at 9 ("This requires us to analyse [sic] foreign culture and differentiate with a serious and scientific attitude, and help audiences to absorb the essence and discard the dross.").

127. Not surprisingly, Islamic Iran has also found Western satellite broadcasting to be particularly destructive and at odds with its own cultural values:

At the moment, the main use that is being made of satellites by the enemies of nations, even nonIslamic nations, is bad use which casts a shadow over the national dignity of all nations, especially Islamic nations. They wish to impoverish us and to impose the wrong and hollow culture of the West, which deprives people of any kind of humanity

[T] he bulk of the enemy onslaught against us, against our brave nation, is a cultural onslaught .... [B]ecause the bulk of the enemy's onslaught is being conducted by audio-visual means, those same satellite channels - the best antidote to which is the good and attractive programmes which the Voice of Vision [Iranian state TV] should broadcast

Majlis Official Comments on Bill Banning Use of Satellite Programme Receivers, BBC SUMMARY OF WORID BROADCASTS, Dec. 20, 1994, LEXIS, News Library, BBCMIR File (excerpting weekly radio programme, entitled "The Nations House," on December 18, 1994 and broadcast on the Voice of Islamic Republic of Iran).

Satellite transmission, broadcasting the programmes of foreign television networks, is not designed to increase the scientific knowledge of nations. Rather it has been developed to mislead youth.... They sell obscene films either at a very low price or give it to you free of charge, whereas the scientific films are so expensive that one cannot afford to buy them. They [the West]
do not transfer their knowledge. They do not transfer their experience of modernizing do not transfer their knowledge. They do not transfer their
technology. What they transfer is what drags families into corruption Emani-Kashani: West Interest in Transfer Not of Technology But of Corruption, BBC SUMMARY OF WorID BROADCAST, SepL 19, 1994, LEXIS, News Library, BBCMIR File cited in Market for Loyalties, supra note 111 , at 676 n.41 (excerpting a prayer sermon delivered by Ayatollah Mohammad Emati-Kashami on September 16,194 at Tehran University and broadcast on the Voice of Islamic Republic of Iran). In light of the tragic events of September 11, the threat Muslim states fear from Western media should be taken seriously. 
sufficient market power over loyalties to assure its continued existence. ${ }^{128}$

During the beginning and throughout the late twentieth century, states restricted competition through several means other than direct censorship: (1) suppression of broadcasts from outside their borders, ${ }^{129}$ (2) retention of a national monopoly on broadcasting, as in Great Britain and other Eastern and Western European countries, ${ }^{130}$ (3) limitations on the distribution of radio frequencies, ${ }^{31}$ and (4) licensing of broadcasters with required renewals which could be objected. Not all of the means of media regulation are direct and obvious. Consider the fourth strategy with respect to broadcast licensing in the United States:

While the Communications Act of 1934 prohibits the FCC from engaging in censorship, the very process of licensing radio and television stations acts as a major constraint on the competition for loyalties. Competition for federal licenses and the requirement of a renewal (every three years in television's "golden age") inevitably affects the range of views expressed. While that range has been

128. TELEVISION, supra note 111 , at 60

129. For example.

[i]n 1925 an "unauthorized" radio service, using the Eiffel Tower in Paris as its transmission point, broadcast an English-language programme direct to the United Kingdom, with advertising from a London department-store chain, hoping to build at British audience. Immediately, British government and broadcasting interests sought to limit the competition. By the early 1930 s there was a vigorous business in English-language broadcasting, supported by British advertisers, emanating from France and directed at British listeners. To protect the national broadcasting monopoly (and the arrangements with newspaper industry that were inv gover

130. In 1923 the Sykes Committee, established by the British government, stated that 'control of such a potential power over public opinion and the life of the nation ought to remain with the State." Id. at 6 (citing UNITED KINGDOM COMMITTEE OF INQUIRY, SYKES COMMITTEE, SIXTH REPORT (1923)). Hence, the British government retained monopoly control over broadcasting through the BBC. "In Western Europe, the extent of competition for national identities within broadcasting has been finely calibrated, and, until the mid-1970s, was limited primarily to entities controlled by the government or closely related to it." TeLEVISION, supra note 111, at 67. With respect to Eastern Europe,

[t]hese bonds [the close relationship of the state and broadcasting] were strong in the Soviet Union and in post-war Central and Eastern Europe, where the state and broadcasting were the same, or, much to the same effect, were both under the control of the Communist Party. Radio, and then television, were direct. unequivocal instruments of state policy in totalitarian and authoritarian regimes - engineers of the soul, to adapt a phrase used by Stalin with respect to the function of arts. Control of these tools of mass information and persuasion was central to the idea of a commanding state. Not only was broadeasting an instrument of the state, but the government media had exclusive use of the airwaves.

1d. at 8 .

131. The United States uses allocation of frequencies to create scarcity. "Much of American regulation of broadcasting has rested on scarcity grounds. Commentators have derided this rationale because of the manufactured nature of the shortage." Market for Loyalies, supra note 111, at 688, n. 96 (citations omitted). South Africa has used this third strategy:

The easiest and most obvious barrier to entry is a limitation on the number of television channels available for public viewing. A dramatic example of cultural protectionism achieved through a maintained scarcity occurred in apartheld [sic] South Africa, where the government banned television until 1976. The National Party felt that American and British programming would threaten the Afrikaans language and undermine the "multinationalism" of its Bantustan system. Id., at 696, n.144 quite wide, and renewal of licenses is typically automatic, the possibility that a valuable asset could be lost is an effective argument for conformity. ${ }^{13}$

The tools of media regulation are diverse and sometimes even subtle, as their operations are designed to effect a chilling of behavior in response to a perceived risk. In spite of their subtlety, they are potent.

\section{F. Reflecting the Existing Power Structure}

Regulation of media to protect national identity is not necessarily limited to a policy designed to project a single identity. Even highlydeveloped democratic states with pluralistic systems act in such a way as to protect the existing status quo.

Rather than having a single state broadcaster, the Dutch long ago established a complex mechanism that gave each segment of society an unencumbered opportunity to broadcast to its own community first on radio, then on television. Groups competed for broadcast time, with awards linked to the number of members or adherents each group could claim .... As a result, Dutch society remained pluralistic, with each group speaking to its own members and not proselytizing others. ${ }^{133}$

In spite of the pluralistic nature of Dutch media and broadcasting, its power structure sought to restrict new entrants, viewing them as threats to the accepted messages of Dutch identity. ${ }^{134}$ Professor Price describes similar systems in Italy, ${ }^{135}$ Germany ${ }^{136}$ and Belgium. ${ }^{13}$

Not only does media regulation reflect the existing power structure, Professor Price proposes that media regulations only change when: "(1) the existing set of broadcasting laws is inadequate to perform the cartelization function; or (2) the 'national identity' has changed or is

132. Id. at 688 .

133. II. at 678. While some may argue that many democracies described by Professor Price, such as in the Netherlands, do not, in fact, maintain monopoly control of broadcasting, they do function as oligopolies or at least act to make it more difficult for new identities to enter the market.

134. Having lived in the Netherlands and Belgium, the author is personally acquainted with Radio Veronica, which began its operations as a "pirate" radio station on a ship off of the Dutch coast with the phenomenon of pirate radio in the Netherlands and Belgium. See generally Nieck Ammerlaan, Company that Gave Us Radio Luxembourg Still Rocking at 65. SCOTSMAN, Apr, 5, 1996, at 27. available at LEXIS, News Library, All News Group File, and Radio Veronica, a http://www.guernsey.net/ -bebridel/veronica.html (on file with the University of Illinois Journal of Law Technology \& Policy). Professor Price comments on pirate radio:

Included groups [i.e, those that had access to broadcasting medium] sought to protect against the extension of broadcasting rights to groups promoting alternative identities, recognizing that any expansion of the zone of narratives would challenge their ability to maintain the loyalty of their members. As elsewhere in Europe, so-called "pirates" attempted to compete outside the constraints of the legally sanctioned oligopoly by broadcasting radio signals from international waters.

Market for Loyalties, supra note 111, at 678

135. Market for Loyalties, supra note 111, at 671

136. Id. "The [German] statutory ideal is for broadcasting to mirror society's composition, but the

consequence has been a rough parceling out of licenses among dominant political parties." Id.

137. Id. at 680 . 
changing and legislation is necessary to legitimate the new players and, in turn, to protect them against unregulated challenge."138 This represents one of the logically derivable conclusions of the "market for loyalties" theory-media regulation is only altered when (1) prior regulation is inadequate to protect the existing power cartel or (2) a shift in the balance of power occurs.

\section{APPLICATION OF THE ECONOMIC MODEL TO EXPLAIN REGULATION OF THE INTERNET}

Having explained Professor Price's "market for loyalties" theory, and having considered the issue of whether the Internet can indeed be regulated, this paper will now go beyond Professor Price's application of the theory and consider what happens when a monopoly loses control of the market. In applying the "market for loyalties" theory to the problem, this paper will apply an economic analysis, including economic concepts of elasticity and substitutes, to make some general predictions. Specifically, this paper will compare the efficiency of two different markets (for loyalties) and consider the role elasticity plays in each in determining the potential disruption caused by the Internet. ${ }^{19}$

A. Consequences if Government Is Unable to Regulate According to Economic Model

\section{General Predictions}

Generally, Professor Price's "market for loyalties" theory predicts that governments, and their constituent power bases, will attempt to establish monopoly positions wherever possible in controlling information flow over the Internet, and that upon failing to do so, the impact of competition will either force them to compete more effectively

138. Comparative Media Law, supra note 111, at 446 .
139. Price focuses on broadcasting rather than on the Internet when applying his "market for loyalties" theory. He does mention the Internet in several of his articles not all of which deal with the "market for loyalties" theory. See Comparative Media Law, supra note 111, at 463 (brief treatment of Internet in conclusion); Monroe E. Price, The Newness of New Technology, 22 CARDOZO L. REv. 188 (2001) (focus is on Internet, but the single reference to "market for loyalties" theory pertains to technology in general); Monroe E. Price, Information Intervention: Bosnia, the Dayton Accords, and the Seizure of Broadcasting Transmitters, 33 CORNELI INT"L L.J. 67, 106-08 (2000) (refers to Interne within the context of regulating broadcasting and other media as a whole, but makes no reference to the "market for loyalties" theory); TELEVISION, supra note 111, at 227 (relating the statement "the authority society to intervene ... declines with the tailoring of information" to the Internet, but does not applying the "market for loyalties" theory).

Professor Price also briefly acknowledges the importance of elasticity in two of his articles. See Comparative Media Law, supra note 111 , at $465 \mathrm{n} .19$ and Market for Loyalties, supra note 111, at 705 n. 37. for loyalty or receive less of it in exchange for identity. ${ }^{140}$ This is simply an exercise in applying the supply and demand curves used in traditional economics-as the supply of identity (from competing factions and enterprises with the government) increases, its price will fall, assuming that demand does not increase.

For example, in Figure $1,{ }^{141}$ suppose the supply of identity is restricted by a government-imposed monopoly to 5.75 units at point $Q_{m}$ (this point is determined by the intersection of a monopolist's "Marginal Cost" and "Marginal Revenue" curves, which is at point $c)^{142}$ and that the corresponding price that the government charges, in terms of loyalty, is about 17.5 loyalty units (point $P_{m}$ ). ${ }^{143}$ This price at $P_{m}$ is determined by the intersection of a vertical line from $Q_{m}$ and the demand curve (which applies regardless of whether there is a monopoly or competitive market). Upon removal of the monopoly concern, equilibrium and market efficiency is achieved in this example at seven units of identity and about 16 units of loyalty (point $b$ ). Essentially, monopolists "underproduce" and overcharge.

The shaded region bounded by points $a, b$, and $c$ in Figure $1^{144}$ represents the inefficiency in the market-both the underproduction of identity and the artificial inflation of its price. More importantly, the vertical distance between $a$ and $b$ (or $P_{m}-P$ ) represents the instability (from the decline in loyalty) resulting from a government or state's loss of monopoly control over information flow (i.e., loss of control over the supply of identity in the market place). Correspondingly, the horizontal

140. For instance, a decline in loyalty may result in the inability of a government to raise armies. taxes, and generally impose sacrifices on its citizens. Governments may compete more vigorously for loyaity by propaganda or advertising campaigns - for example, roadway and public works signs that say, "paid for by your tax dollars." It may even be argued that recent trends to re-engineer government (such as former Vice President Al Gore's National Partnership for Reinventing hovernment) reflect the need of government to compete for loyalty. See Reinvention Principles, at

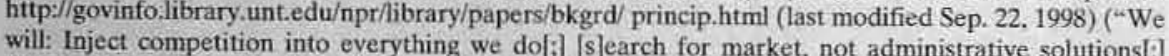
will: Inject competition into everything we do[;] [s]earch for market, not administrative solutions[;] [m]easure our successes by customer satisfaction[.]"). See also Exec. Order No. 12862, 58 Fed. Reg. 8.257 (Sept. 11, 1993).

Putting people first means ensuring that the Federal Government provides the highest quality service possible to the American people. Public officials must embark upon a revolution within the Federal Government to change the way it does business. This will require continual reform of the executive branch's management practice and operations to provide service to the public that

Id (emphasis added). The emphasis clearly appears to be on competing with or "matching" the level 141. See Appendix.

142. See RichARD B. MCKENZIE \& Gordon TUlLOCK, MODERN POLITICAL ECONOMY: AN INTRODUCTION TO ECONOMICS 171 (1978).

143. For monopolies, supply curves and marginal cost curves are identical. See id. at 174 ("When this supply and demand model is converted to represent a monopolist as opposed to a number of competitors, the industry supply curve becomes the monopolist's marginal cost curve and the industry's demand curve becomes the demand facing the sole producer."). The rationale is that a monopoly supplier will set the level of production at the intersection of its marginal cost and marginal revenue. Consequently, a monopolist's supply curve also has to run through this point and ends up exactly following the monopolist's marginal cost curve.

144. See Appendix. 
distance between $a$ and $b$ (or $Q_{m}-Q_{2}$ ) represents the degree of choice that an individual has to select among competing identities in a society.

The implication of governments, and their power constituents, not being able to create an artificially high monopoly price for identity could be significant. The price of identity (as measured in loyalty) that the state needs from its subjects to exact military service, voluntary payment of taxes (as is the case in most democracies), and in some instances, continued residence in the country, ${ }^{145}$ can be quite high. Of course, the alternative for the state is to compete by producing evermore valuable forms of identity (i.e., sold at a greater unit price or by legitimately capturing a larger share of the identity market from its competitors). ${ }^{166} \mathrm{~A}$ strategy of increasing the state's market share of identity (without fundamentally changing or introducing new kinds of identity as products) will not shift the demand curve or increase price, in terms of loyalty, nor will it make the state more profitable (since the state would have to expand its production to where marginal cost exceeds the marginal revenue). ${ }^{147}$

Having addressed the general consequences of Professor Price's "market for loyalties" theory and having considered the implications of regulating the Internet, this article will now examine some specific cases.

\section{Predictions for Singapore's Efforts}

Given the difficulty in regulating the Internet, and the general implications of the failure to limit competition (as per the "market for loyalties" model), what predictions might be made about Singapore's efforts to regulate the Internet? Generally, loyalty falls with increased competition for identity, but how much, and would such a drop have a significant effect?

Professor Price's theory tells us that if Singapore is successful it will be able to exact a higher price in the exchange of loyalty for identity. There is a cost to maintaining a monopolistic hold on the flow of information: the economic, educational, and scientific advantages of the Internet may not be fully realized. As illustrated in the case where Germany successfully coerced one of its ISPs (T-Online) to ban access to

145. For instance, the Federated States of Micronesia has been losing significant population to higher paying jobs and standards of living in other countries. About $19 \%$ of its citizens live abroad. See General Information on the Federated States of Micronesia: People, at http://www.fsmgov.org/info/people.html (last modified Mar. 1, 2002) (copy on file with the author). Its net migration rate is more than $43 \%$ of its birth rate. Compare CENT. INTELLIOENCE AGENCY, WORID FACTBOOK 1999, at 324 (1999), with THE STATESMAN'S YEARBOOK: THE POLITCS. CULTURES AND ECONOMIES OF THE WORLD, supra note 22, at 1129 (11.65 net migration rate divided by 27.09 birth rate).

146. See Reinvention Principles, supra note 140.

147. See Figure 1 in Appendix. By capturing increased market share, with nothing more, the state moves production from Qm to Qc, but by so doing, it ventures along its marginal cost curve to points where marginal cost exceeds marginal revenue (for example, point $c$ to point $b$ in fig. 1 ). certain neo-Nazi sites, the consequence was that more than one thousand unobjectionable sites were also banned because of the inability to selectively filter sites. ${ }^{148}$ The reaction of the Internet community (by setting up mirror sites at universities) ${ }^{149}$ compounds the problem because banning these additional sites will inevitably lead to the inability to access useful economic and scientific information on sites hosted by university servers. As General MacArthur is said to have protested during the Korean war, it is impossible to bomb "half of a bridge" -it's the whole bridge or nothing. ${ }^{150}$

In the end, Singapore's efforts to impose liability on ISPs under a "best endeavors" standard may prove to be a fairly ineffective sieve. Blocked sites, which cannot be blocked with any surgical precision, are commonly "mirrored" at university sites, ${ }^{151}$ access to which is vital to Singapore's continued growth. ${ }^{152}$ "Best endeavors" may quickly be reduced to a "one-time" blocking rule and lead to the distribution of screening software to Internet users - not a great hurdle to the flow of information over the Internet.

Assuming that Singapore is unable to regulate the flow of information via the Internet, what are the consequences? According to Professor Price's model, the price of identity as paid in loyalty will have to drop. Singapore is the 13 th largest trading country in the world, has an unemployment rate of about $3.5 \%$, and receives no aid from the United States. ${ }^{1.33}$ Political loyalty is more easily purchased by the incumbent regime in a strong economy. Singapore's government already competes for identity as a result of commercial advertising. ${ }^{154}$ In essence,

148. See Delacourt, supra note 5, at 213; see also supra text accompanying note 41 .

149. See Delacourt, supra note 5 , at 214 ; see also supra text accompanying note 41. 150. MacArthur's alleged statement, or a form of it, may have been made (perhaps at first) by an bridges (leading an Air Force wag [wireless air gunner] to cracke thow the 'Korean end' of the bridge?')" CLAY BLAIR, JR. MACARTHUR 321 (1977) Sec] to crack: "how do you bomb one end of a ARMY IN THE KOREAN MACARTHUR 321 (197). SeE alsO JMMES F. SCHNABEL, UNTTED STATES http://www-army.mil/cmh-po/books: POLICY AND DIRECTION: FIRST YEAR 241 (1992), at http:/ www-army.mil/cmh-pg/books/pd-c-13,htm (last modified Aug. 13, 1996) (citing USAF Hist. 1952, ch. 1. p. 22.), Roy E. A A Prifman Operations in the Korean Conflict. 1 November 1950-30 June 1952, ch. 1. p. 22.), ROY E. APPLEMAN, UNTTED STATES ARMY IN THE KOREAN WAR: SOUTH TO THE NAKTONG, NORTH TO THE YALU 716 (1992), ar http://www. army.mil/cmh-pg/books/korea/20-2Ironically MacArto

Ironically, MacArthur's forces (Navy "Skyraider" bombers) did manage to bomb just "half of a bridge," even limiting their bombing to the Korean side. See Naval Historical Center, Carrier Air Strikes 15 Sept. - 25 Nov. 1950, photo nos. 80-G-421972 and 80-G-422112, and accompanying text, at http:/(www.history.navy, mil/photos/events/kowar/50-unof/un-2a htm (last modified Dec. 19, 1999). The author's point remains, nonetheless. It is just as impractical to cross a bridge that has one end destroyed as one that has been destroyed at both ends. With reference to the Internet, you cannot selectively deny access.

151. For examples of the use of mirror sites to circumvent censorship, see supra note 6.

152. See supra notes $88-91$ and accompanying text.

153. Bureau of East Asian and Pacific Affairs, U.S. Department of State, Background Nores: Singapore, August 1999, at http//www.state.gov/www/background_notes/singapore_0899_bgn.html (last moditied Aug. 11, 1999).

154. See supra text accompanying note 126 . 
Singapore may have a fairly horizontal (or "elastic") demand curve for the identity it exchanges for loyalty. ${ }^{15}$

In other words, increased competition for identity may not result in significant reduction in the amount of loyalty which Singapore's citizens are willing to pay in exchange. Suppose that as a result of widespread Internet access in Singapore, the existing power structure loses much of its ability to control the flow of information, and consequently, there is an influx of competing identities (i.e., political and social agendas at odds with the values officially espoused by the existing government of Singapore). In Figure $2,{ }^{156}$ movement from point $a$ (in which the state has established monopoly control over identity, thus keeping the price artificially high) to point $b$ (or equilibrium as a result of the Internet's introduction of competing identities into the market for loyalty) does not have a dramatic destabilizing effect. The vertical distance (representing the drop in price in terms of loyalty) between $P_{m}$ and $P_{\mathrm{c}}$ is minuscule. The shaded area representing the inefficiency in the market is also relatively small. In addition, note that the declining slope of the marginal revenue curve (the intersection of the marginal revenue and marginal cost curves at point $c$ determines the level of production along the demand curve or point $a$ ) is purely a function of the demand curve. ${ }^{157}$ Consequently, it is not really an additional, independent variable affecting the degree of instability (or drop in the price, in terms of loyalty) caused by the shift to equilibrium. Assuming a horizontal demand curve, the effects of free information flow will not have any significant destabilizing effects.

The major factor in determining elasticity is the presence of substitutes. ${ }^{158}$ The argument, in economic terms, is that Singapore already has an abundance of substitute identities (beyond those supplied by its government) as a result of Singapore's long embrace of free markets and Western commercial culture. ${ }^{59}$ Another argument is that Singapore's citizens, as a result of their superior economic status, are able to expend more on competing identities and, consequently, are not required to cut back on expenditures of loyalty in favor of the government. In essence, it is not simply an "either-or" proposition as characterized in a static "pie chart" economy, but an issue of dynamic economies in which the amount of resources which citizens have to spend

155. In economics, the pitch of a demand curve is referred to as its "elasticity." The more horizontal the curve, the more the demand is said to be elastic. See MODERN POLITICAL ECONOMY, supra note 142 , at 41 , fig. 3.3 .

156. See Appendix

157. See id. at 172. In fact, the marginal revenue curve always falls at twice the rate of the demand curve.

158. $1 d$. at 43 .

159. For a discussion of how commercial enterprises provide competing identities, see supra text accompanying notes $122-127$. is inconstant and capable of significant growth. ${ }^{160}$ Hence, the conclusion that Singapore will not be significantly affected by free information flow is compatible with economic concepts such as "elasticity" and "substitutes," which justify the use of a relatively horizontal demand curve.

\section{Predictions for China's Efforts}

China's efforts to regulate the Internet, in comparison to Singapore's exertions, are more comprehensive. ${ }^{161}$ The risk of destabilization likewise is greater. China's strategy for controlling information flow has been two-fold: (1) "limiting access to a manageable number of users" such as professionals, and (2) the creation of a "secure network in which Chinese users will have unlimited access to each other," but behind a software firewall which blocked objectionable material from the outside world. ${ }^{1 / 2}$ These strategies have been criticized for reasons similar to those relating to Singapore's efforts - the difficulty in surgically blocking some sites while still being able to access economically and scientifically valuable sites, such as those found at universities. $^{163}$

Assuming that China is unable to regulate information flow over the Internet, what are the consequences? China's economy, although rapidly growing, is not as strong (in proportion to its size) as that of Singapore. It has an estimated urban unemployment rate of roughly ten percent, external debt of $\$ 162$ billion, and exports of $\$ 232$ billion $^{164}$ (compared to tiny Singapore's $\$ 137$ billion in exports), ${ }^{165}$ and Gross Domestic Product ("GDP") per capita of $\$ 3,600^{166}$ (compared to Singapore's per capita GDP of $\$ 26,500)^{167}$ Thus, China is not in as secure a position as Singapore. If China wants to compete with the identities offered by Western commercial culture like Singapore, whose advertising and media reflect a much higher per capita GDP, ${ }^{168}$ it may find that the price of identity drops significantly. In essence, China's demand curve for identity may be inelastic, and as a result, the price of loyalty may fall precipitously with increased competition. ${ }^{169}$

160. See infra note 178 (discussing array of factors affecting elasticity including aggregate income and marginal consumers)

161. In spite of China's rigorous effort to regulate the Net, there is evidence of profound impact of the Internet in China. See supra note 110 and accompanying text.

162. Delacourt, supra note 5, at 217-18. See also KALATHIL \& BOAS, supra note 69.

163. See supra notes $22,148-149$ and accompanying text.

164. See CENT. INTELLIGENCE AGENCY, CIAWORLD FACTBOOK 2001106 (2001) [hereinafter CIA WORLD FACTBOOK].

165. Id. at 453 .

166. $H$. at 105

167. Id. at 453

168. See, e.g., supra note 126 and accompanying text.

169. For a discussion of elasticity, see supra notes $155-157$ and accompanying text 
The potential risk of destabilization as a result of the Internet (and the introduction of competing identities) is significantly greater in China than in Singapore. In Figure $3,{ }^{170}$ the relative inefficiency (and potential for destabilization) in the "market for loyalties" (when compared to Singapore in Figure $2^{171}$ ) is indicated by the shaded area bounded by $a, b$, and $c$. Movement from point $a$ (which is artificially maintained by monopoly) to point $b$ (equilibrium), even though only representing a 1.5 unit increase in identity (the distance from $Q_{m}$ to $Q_{c}$ ), produces significant discord (a four-unit decrease) as a result of the reduction in the price of loyalty (or the distance from $P_{m}$ to $P$ ). Note if the demand curve for China is steeper than for Singapore, as has been argued above, then the marginal revenue curve, which is solely derived from the demand, will also become much steeper. ${ }^{1 / 2}$ Because the marginal revenue curve shifts with the demand curve, it is not an independent variable in accounting for the degree of instability caused by increased competition among suppliers of identity.

Destabilization of a country of 1.2 billion people naturally should give us pause, ${ }^{173}$ particularly in light of the tumultuous history in Russia and the former Soviet states since the era of Glasnost. It may be that China needs incremental exposure to Western culture before it is ready for unrestricted access to the Internet and Western culture. On the other hand, it may be impossible to restrict access to information over the Internet. This would lead to the unavoidable consequence that China may have to compete more aggressively for the loyalty of its citizens, who may become increasingly enamored with Western culture. Such a cycle would necessitate yet further reform. The failure to compete effectively will ultimately result in a shift of power and political destabilization.

\section{Extrapolating from Elasticity-Additional Theorizing}

The hidden premise presented in the Singapore and China examples above is that inelasticity, or a sudden dramatic drop in loyalty as a result of an increased supply of identity, equates to political instability since the state must work harder to win loyalty or risk losing its market share, thus ending up in a weaker position. Given that the principal factor in determining elasticity is the presence of substitutes, ${ }^{174}$ it may be extrapolated that the political instability resulting from an increased supply of identity (and shift in price) is inversely related to the prior

penetration of competing sources of identity (or substitutes) in the market. This may be expressed as a function:

$$
i=f\left(\frac{k}{p}\right)
$$

where "i" is the instability, " $\mathrm{k}$ " represents the level of new competing identities being introduced, and " $\mathrm{p}$ " is the penetration of previously competing identities, or substitutes, into the market. ${ }^{176}$ Eventually, in a state that opens itself to competing identities, if " $p$ " were to approach infinity, the level of disturbance will grow infinitesimally small ${ }^{177}$ (at least with respect to the instability caused solely by the introduction of new identities): ${ }^{178}$

175. The relationship is expressed as a function because it is incomplete. For instance, the author's arguments about the economic viability of Singapore and China, in comparison to each other have not been taken into account in the formula. See supra notes 153.155 and 164-167. and accompanying text. Perhaps economic viability is indirectly accounted for by the factoring in of substitutes or "p." It can be argued that healthier economies are more open and are amenable to the presence of substitute or competing identities. However, much more information and study is needed to establish such a relationship.

In addition, no accounting is made for the impact of marginal revenue as a separate variable, which is used to determine where a monopoly will set its level of production on its demand curve. This is because marginal revenue is directly derived from the demand curve and is not an independent variable. See supra note 156 and accompanying text.

176. For purposes of simplicity, this paper will not consider factors such as disparate "marginat utility of equivalent quantities substitute goods," Marco Fanno, The Elosticity as disparate "margina utility of equivalent quantitics substiture goods, Marco Fanno, The Elassicity of Demand of Substitute Goods, 3 ITALIAN ECON. PAPERS 99, 101 (1998) [hereinafter Elasticity. or "adulterated substitutes," in which the consumer has an incomplete knowledge of the character of the goods, Carl L. Alsberg. Economic Aspects of Adulteration and Imitation. 46 Q. J. ECON. 1 (1931).

177. The argument that elasticity or stability increases with additional substitutes was demonstrated in economic literature in 1926 by the Italian economist Marco Fanno. The findings are presented with detailed mathematical analysis. Marco Fanno, Contributo Alla Teoria Economica dei Bemi Succdanei, 2 ANNALI DI ECONOMIA 331 (1925-26). Although the author was unable to find an English translation of this important work, a shorter version was originally published in German. Marco Fanno, Die Elastizität der Nachfrage nach Ersatzgütern, ZFITSCRIFT FUR NATIONALOKONOMIE, 1939, at 51-74. An English version of Fanno's translation of this article exists. See Elasticity, supra note 169. Fanno's conclusions after rigorous theoretical analysis are stated: The conclusion given above refers to the instance of two goods only. But it also applies to the instance in which a good may have more than one substitute, that is for the instance of more than wo goods. In this case the action of each of them accrues with the others and the elasticity of demand for each of them is, other conditions being equal, all the greater the number of its substitutes.

1d. at 115. The importance of Fanno's contribution has been recognized in American economic iterature. Alsberg, supra note 176, at

$$
\lim f\left(\frac{k}{p}\right)=0
$$

This is because a portion of the formula, namely the other factors which impact elasticity and instability, are unknown. See infra note 179. All that is known is that the instability resulting from the introduction of new identities will approach zero if, in theory only, the number of previously introduced identities approaches infinity. See infra note 183 and accompanying text (explaining why the number of previously introduced identities will never reach infinity). 


$$
\lim \left(\frac{k}{p}\right)=0
$$

Hence, a state in which a diversity of identities flourishes is a supremely stable one, at least mathematically, with respect to the instability caused by the introduction of new identities. ${ }^{179}$

The novelty of the conclusion that stable states are inherently more diverse is illustrated by the traditional Dutch maxim, "Eendracht Maakt Magt," or "Unity Makes Might.," ${ }^{180}$ It would have been very odd for Europe, or anywhere else for that matter, to have adopted as a maxim, "Diversity Makes Might." The inscription, E Pluribus Unum, or "out of many one," on United States coinage and the Great Seal of the United States bears similar connotations. In stark contrast to Western historical ideals, one historian argues that the rise of Europe to global ascendancy in the latter half of the second millennium is largely attributable to its diversity:

Why was it among the scattered and relatively unsophisticated people inhabiting the western parts of the Eurasian landmass that there occurred an unstoppable process of economic development and technological innovation which would steadily make it the commercial and military leader in world affairs?

... The one feature of Europe which immediately strikes the eye when looking at a map of the world's "power centers" in the sixteenth century is its political fragmentation.... This was not an accidental or short-lived state of affairs.... Europe had always been politically fragmented, despite even the best efforts of the Romans .... ${ }^{181}$

Hence, there is some historical evidence supporting this remarkable derivation of "market for loyalties" theory. Certainly, a much more

179. The sources of instability (as a result of a dramatic shift in demand as represented by loyalty) probably cannot be confined simply to the effects of new identities being introduced into the market for loyalty. See, e.g., William Novshek \& Hugo Sonnenschein, Marginal Consumers and Neoclassical Demand Theory, 87 J. POL. ECON. 1368 (1979) (naming "aggregate income" and "margina consumers" - i.e., the change in the number of consumers in relation to price - as important factors to elasticity in addition to substitution). See also supra note 160 and accompanying text (suggesting how elasticity in addition to substitution). such factors translate into the market for loyalties another reason why the instability relationship to identity must be expressed as a function identity being a complete equation. However, the equation is useful in determining the effects of Internet.

180 . See, e.g.. N.Y. LAW \& 30-a (2001) (the Seal of King's County which bears the maxim is 180. See, e.g.. N.Y. LAW $\$ 30-a$ (2001) (the Seal of King ' County which bears the maxim is attributed to its Dutch heritage). The author was given a pewter dish bearing royal insignia of Belgium which also bears this phrase. Another example of a Dutch proverb is "Waar de eendrach ontbreekt, loopt de kracht op krukken," which mea

MESTERS, PRISMA SPREEKWORDEN BOEK S4 (1964). 181. PAUL KENNEDY, THE RISE AND FALL OF vigorous historical analysis (as well as consideration of other factors) is required to confirm this conclusion. ${ }^{182}$

Notwithstanding the additional stability brought about by increasing diversity of identities, there is a point at which sources for substitute identities will not enter the market. "In none of these [c]ases can the price, in the long run, rise beyond the level which induces further entry, and the profit-maximizing price may lie considerably below this upper limit." ${ }^{183}$ As a corollary, in no case will the supply of identity substitutes rise above a level at which no additional suppliers would enter the market at the going rate of exchange for loyalty (i.e., above the "profitmaximizing price").

In the end, the mathematical expression of the relationship of instability to substitute identities is a formal and concise way of saying what is intuitive to most everyone, that it is roughest at the beginning for societies in the process of opening themselves to competing visions of identity, and as a corollary, that the most restrictive regimes experience the greatest turmoil from the presence of new sources of identity. ${ }^{184}$ The implications for the Internet are profound. Authoritarian states, with a history of restrictive regulation of information flow, will experience the greatest instability because of the introduction of competing identities. On the other hand, states that attempt to seal themselves off from such a challenge by "firewalling" themselves from contact with the rest of the world, or limiting Internet access to an elite few, risk missing the fruits of Internet connectivity and falling further behind in the race to close the "information gap" with Western countries. ${ }^{155}$

182. For the sake of argument, the author has intentionally equivocated unity with a lack of diversity (having done so because this is a common misconception). However, unity has no meaning diversity (having done so because this is a common misconception). However, unity has no meaning
or value except within the context of diverse parties. The proposition that a monolith is united is ot value except within

183. William FeLINer, COMPETITION AMONG THE FEw 49 (1960) (earlier edition quoted in 183. WILLIAM FELINER, COMPETINION AMONG THE FEW 49 (1960) (earier edition quoted
part in William D. Arant, Competition of the Few Among the Many, 70 Q. J. ECON. 327, 336 (1956)). part in William D. Arant, Competition of the Few Among the Many, 70 Q. J. ECON. $327,336(1956)$ ).
184 . In pure economic terms, "the elasticity of demand for A, that is of a good for which there is a substitute, is first of all greater than the demand elasticity would have been if the substitute were not
s. substitute, is first of all greater than the demand elasticity would have been if the substitute were not
present." Elasticity, supra note 176, at 115. In other words, there will always be less of a shock at the present." Elasticity, supra note 176 , at 115 . In other words, there will always be less of a shock at the
introduction of new identities into the "market for loyalties" if existing competing identities are introduction of new identities into the "market for loyalties" if existing competing identities
already present. In essence, economics provides us with a mathematical argument for free speech. already present. In essence, economics provides us with a
185 . See supra notes $162-163$ and accompanying text. 
B. Comparison to the "Market for Eyeballs," the "Collective Action" Problems, and the Problem of "Externalities"

In modern economic theory, collective action, prisoner's dilemma and externalities problems (among other issues) challenge the classical economic assumption that individuals will always make rational choices to maximize their interests. The trouble is that there is a "divergence between individual and collective rationality" as seen in collective action and prisoner's dilemma problems.

For a long while, economists, like specialists in other fields, often took it for granted that groups of individuals with common interests tended to act to further those common interests, much as individuals might be expected to further their own interests ...

More recently, the explicit analysis of the logic of individual optimization in groups with common interests has led to a dramatically different view of collective action. ${ }^{18}$

This quandary is not simply speculative in nature, but a practical problem that has been duly noted in the debate surrounding the government's need to mandate public interest television.

[P]ublic interest programming can produce social benefits that will not be adequately captured by the individual choices of individual citizens; the same is true for programming that produces social costs, including apathy, fear, and increased criminal activity.

Because of the collective action problem, an unregulated market will underproduce public goods and overproduce public bads. ${ }^{188}$

Applying the analysis of collective action and externalities problems, the explanation for government's effort to regulate information flow stems from the need to protect the demand for its public goods (i.e., it is in the public's interest to receive a uniform message from broadcasters and publishers supporting policies and values approved by the state), rather than from a drop in price (in terms of loyalty) as is the case in Professor Price's "market for loyalties" theory. Using contemporary terminology, the state must preserve its share in the "market for eyeballs." collective action and externalities problems is simpler, why is it not the better explanatory theory?

In addition, a fundamental assumption of neoclassical economicsthe effectiveness of unregulated individual choice to maximize utility - is brought into question by collective action and externalities problems. These problems and modes of analysis, through coincidence or

186. Anatol Rapoport, Prisoner's Dilemma, 1 NEW PALGRAVE DictionaRY OF ECON. 973, 974 (1987, rev. 1991)

187. Mancur Olson, Collective Action, 3 New PaLgrave Dictionary of ECON. 474 (1987, rev. 1991).

188. Sunstein, supra note 113 , at 517 .

189. See supra note 113 and accompanying text. otherwise, have been associated with the "market for eyeballs." 190 The explanation for disruption in the market for eyeballs, as a result of government's inability to regulate information flow, is attributed to a market failure as a result of the "disparate rationality" of individual and collective decisions (i.e., what is good for the group is not necessarily the maximum choice for individual, thus resulting in defections from the group). ${ }^{191}$ On the other hand, in the "market for loyalties" theory, as set forth in this paper with reference to elasticity, the explanation for market disruption is not seen as a market failure, but as a result of an inelastic demand curve.

While it may seem that the superior theory must contemplate modern modes of analysis, such as the problem of collective action and externalities, neoclassical economics need not be hastily cast aside. Neoclassical economists do qualify their assertions with reference to such considerations. ${ }^{192}$ In addition, these economists do not seem to be greatly troubled by the challenge to rationality, which is one of their fundamental assumptions.

Economists have answered this criticism [to the assumption of rationality] in a number of ways, first by pointing out that the requirement of rationality in economics is actually a very low requirement. Second, Gary Becker has argued that the demand and supply relationship can be generated by random behavior: hence people do not have to be rational to fulfill the basic postulates of economics. This argument by Becker was criticized in part by Israel Kirzner, but the basic point is generally accepted. ${ }^{19}$

For neoclassical economists, rationality is reduced to postulating that "human's demand curves slope downward and that they will select the

190. See Sunstein, supra note 113, at 516-17. There is no reason why "market for eyeballs" is inherently more compatible than "market for loyalties" theory with modern modes of analysis such as collective action problems and problems of externalities. Nor is there any reason why "market for oyalties" theory is better suited than "market for eyeballs" to concepts of elasticity and neoclassical assumptions except for tradition (i.e., the historical absence of discussion of elasticity in "market for eyebails" literature), and perhaps the early development in "market for loyaities" theory of the concept of exchange of loyalty for identity, concepts which easily lend themselves to elasticity "Market for eyeballs" has never expressly clarified what is exchanged for eyeballs other than the general implication of television programming. For the sake of developing his arguments, the autho has chosen to continue the traditional association of "market for eyeballs" with collective action and xternalities problems, and "market for loyalties" theory with neoclassical assumptions.

191. Rapoport, supra note 186, at 974 (discussing "Prisoner's Dilemma" and "Tragedy of the Commons").

192. See, eg., Richard B. MCKENZIE \& GORDON TULLOCK, NEW WORLD OF ECONOMICS: EXPLORATIONS INTO THE HUMAN EXPERIENCE 176 (3d ed. 1981) [hereinafter NEW WORLD OF ECONOMTCS: EXPLORATIONS] ("The market, if there are no monopolies or externalities present, is so organized that the individuals attempting to benefit themselves end up benefiting others:")

193. RiCHARD B. MCKENZIE \& GORDON TULLOCK, THE BEST OF THE NEW WORLD OF ECONOMICS... AND THEN SOME 52 (5th ed. 1989) [hereinafter BEST OF THE NEW WORLD OF ECONOMICS] (citing Gary S. Becker, Irrational Behavior and Economic Theory, $70 \mathrm{~J}$. POL. ECoN, (1962), Israel M. Kirzner, Rational Action and Economic Theory. 70 J. POL. ECON. 380 (1962), and Gary S. Becker, A Reply to Kirzner, 71 J. PoL. ECON. 82 (1963)) 
preferred choice over the less preferred." ${ }^{104}$ Hence, neoclassical economics remains a respectable discipline.

The crux of the matter is whether an externalities problem should cause us to discard the "market for loyalties" theory, and more specifically, whether the theory is applicable to analysis of the impact of the Internet. While the problem of externalities is readily apparent with respect to public interest television (without government regulation, stations would decline to supply such programs in favor of those that attract wider audiences and, hence, advertising dollars), the situation is markedly different with respect to the Internet because commercial advertising dollars are not necessary to fund government Web sites and content is not dictated by viewer ratings. Adopting the "market for loyalties" analysis, it could be argued that externalities exist with respect to the exchange of identity for loyalty, since a "socially beneficial" and unified message of identity projected by the government has many external beneficiaries. However, such an argument is inconsistent with the values of a pluralistic society, which on the whole would find such an arrangement to be disadvantageous. In summary, the conditions creating an externalities problem for public interest television programming are not universally applicable and do not apply to the Internet. Consequently, there is no reason to discount "market for loyalties" theory or neoclassical economics as a useful tool for considering the impact of the Internet.

The real question is whether one theory is superior to the other because it is simpler or it explains more. As thoroughly discussed above, the "market for loyalties" theory makes predictions as to the degree of disruption caused by government's failure to regulate information flow, depending upon the degree to which competing identities have already established themselves within the market (i.e., the extent of openness of the society). The question is whether such predictions can be made using the analysis employed in collective action and externalities problems.

Collective action analysis does make predictions about when defections (resulting in a market failure and disruption) will occur based on the size of membership in the group. Essentially, as group membership grows, all other things being equal, "the incentive to act collectively diminishes. ${ }^{195}$ This is because eventually "the failure of one individual to support collective action will not... have any perceptible effect on the incentive any other individual faces...." Whic providing useful insight, both the "market for loyalties" and the "market for eyeballs" theories contemplate vast markets (e.g., the citizens of a state). The issue is not simply if there will be disruption at the point when a government can no longer regulate information flow, but how

194. BEST OF THE NEW WORLD OF ECONOMICS, supra note 193, at 52 different societies will fare, depending upon their respective degrees of openness (i.e., the number of previously competing identities in their market places). To this extent, the "market for loyalties," as described in this paper to include concepts of elasticity, provides us with a better theory because it explains more than the traditional "market for eyeballs" theory.

\section{CONCLUSION}

The Internet may prove to be particularly difficult to regulate since its nature is to circumvent blockages in information flow. In spite of identifiable boundaries provided by ISPs, which may be subject to liability by territorial governments, the advent of mirror sites (especially at universities), alternate means of routing, and the sheer volume of the Net, when coupled with an inability to effectively filter "objectionable" sites (without blocking unoffensive, technical, and economically valuable sites), makes significant regulation of the Internet uncertain at best. The dilemma has become how to take economic advantage of what the Net provides, while simultaneously screening undesirable information. The impossibility of doing so has become an instance of "having one's cake and eating it too."

Professor Monroe Price presents a "market for loyalties" economic model in which governments and their constituent power holders trade identity (consisting of the dreams, hopes, and heritage of their citizens) for the loyalty of their subjects. In this market, governments and power holders are sellers, citizens are consumers, the currency is loyalty, and the product being purchased is identity. Governments traditionally establish monopoly positions to limit competing identities, thus ensuring a high price in terms of loyalty for their efforts. Ultimately, regulatory change only occurs when existing regulatory limitations are ineffective to protect the existing power structure, or when there has been a shift in that structure involving new members.

This paper has sought to break new ground by applying the "market for loyalties" theory to the Internet under circumstances in which there is a loss of monopoly control over the flow of information. Generally, Professor Price only applies his theory to monopolistic or oligopolistic "markets for loyalty," such as in international and satellite broadcasting in authoritarian states. The "market for loyalties" theory (if it incorporates consideration of elasticity, as it does in this paper) is a potent tool in explaining the consequences of a state not being able to impose monopoly control over information flow. Governments, and their constituent power holders, caught off guard by the Internet's power to circumvent censorship controls risk destabilization when the loyalty that their subjects are willing to expend is diminished by an increased supply of identity from competing enterprises and factions from points all over
the globe. 
The potential effects on China and Singapore, both of which regulate (although in significantly varying degrees) the flow of information over the Internet, if such regulation is unsuccessful, will deviate widely depending on the shape and pitch of their respective supply and demand (or loyalty and identity) curves. Arguably, Singapore's demand curve is elastic as a result of its developed and robust economy and the fact that it is more likely to have already experienced significant exposure to and participation in Western commercial culture. In contrast, China is more susceptible to destabilization as the result of an arguably inelastic and steeper demand curve. Indeed, as proposed in this paper, the degree of instability caused by the advent of new sources of identity is an inverse function of the prior penetration of competing identities, which function can be expressed as follows:

$$
i=f\left(\frac{k}{p}\right)
$$

where " $i$ " is identity, " $k$ " represents the level of new competing identities being introduced, and " $p$ " is the penetration of previously competing identities, or substitutes, into the market. Further extrapolation of this theory reveals that the instability caused by each additional identity decreases with an increasing number of competing identities in the market-a kind of mathematical justification for free speech, diversity, and tolerance.

The "market for loyalties" theory, if extended in its application as it is in this paper (including consideration of elasticity), serves our changing information society well. It gives us greater understanding and rudimentary tools for predicting the consequences of unimpeded information flow. Consequently, application of the "market for loyalties" theory merits serious consideration for any interested pundit or self-proclaimed prophet of the information age.

V. APPENDIX

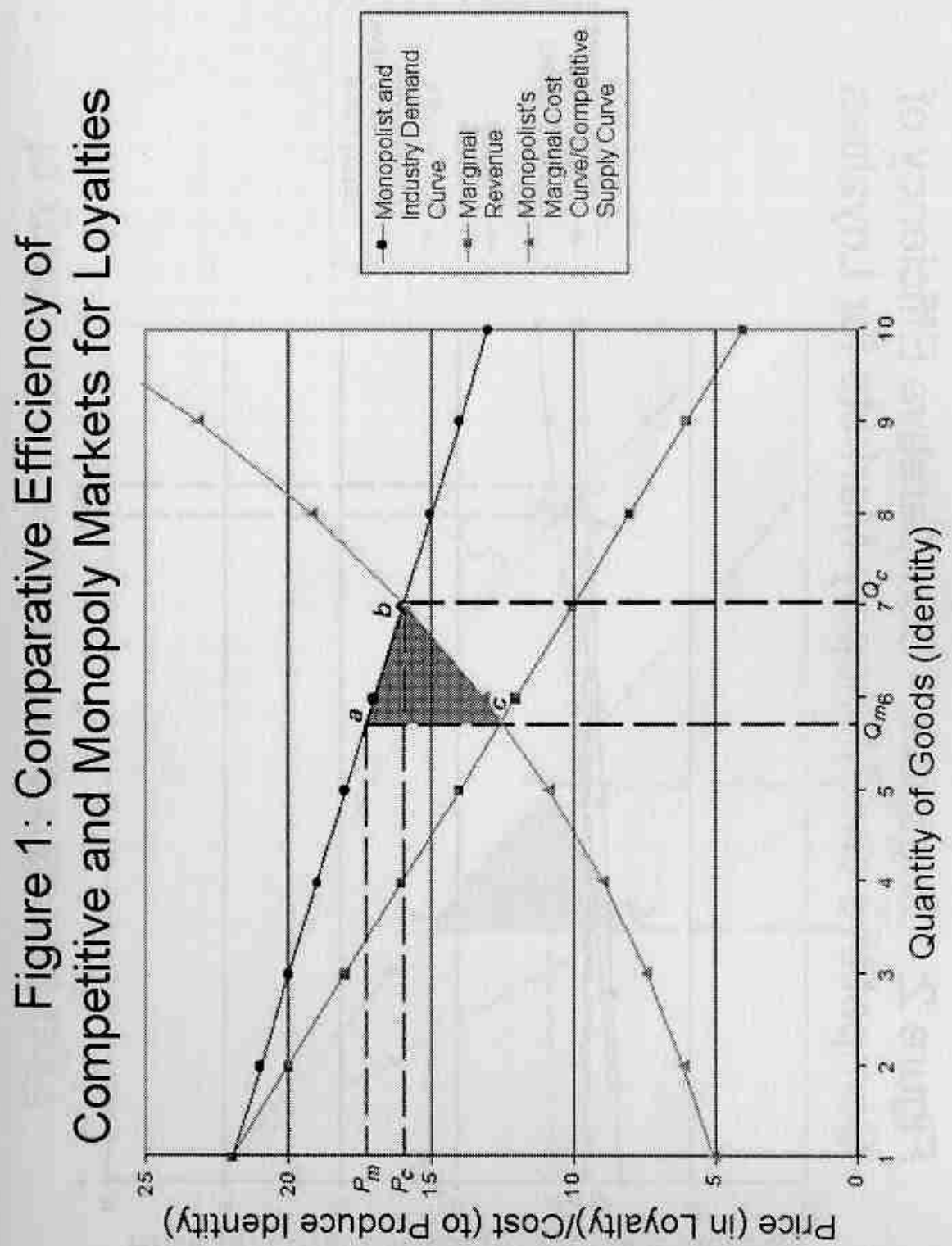


Figure 2: Singapore - Comparative Efficiency of Competitive and Monopoly Markets for Loyalties

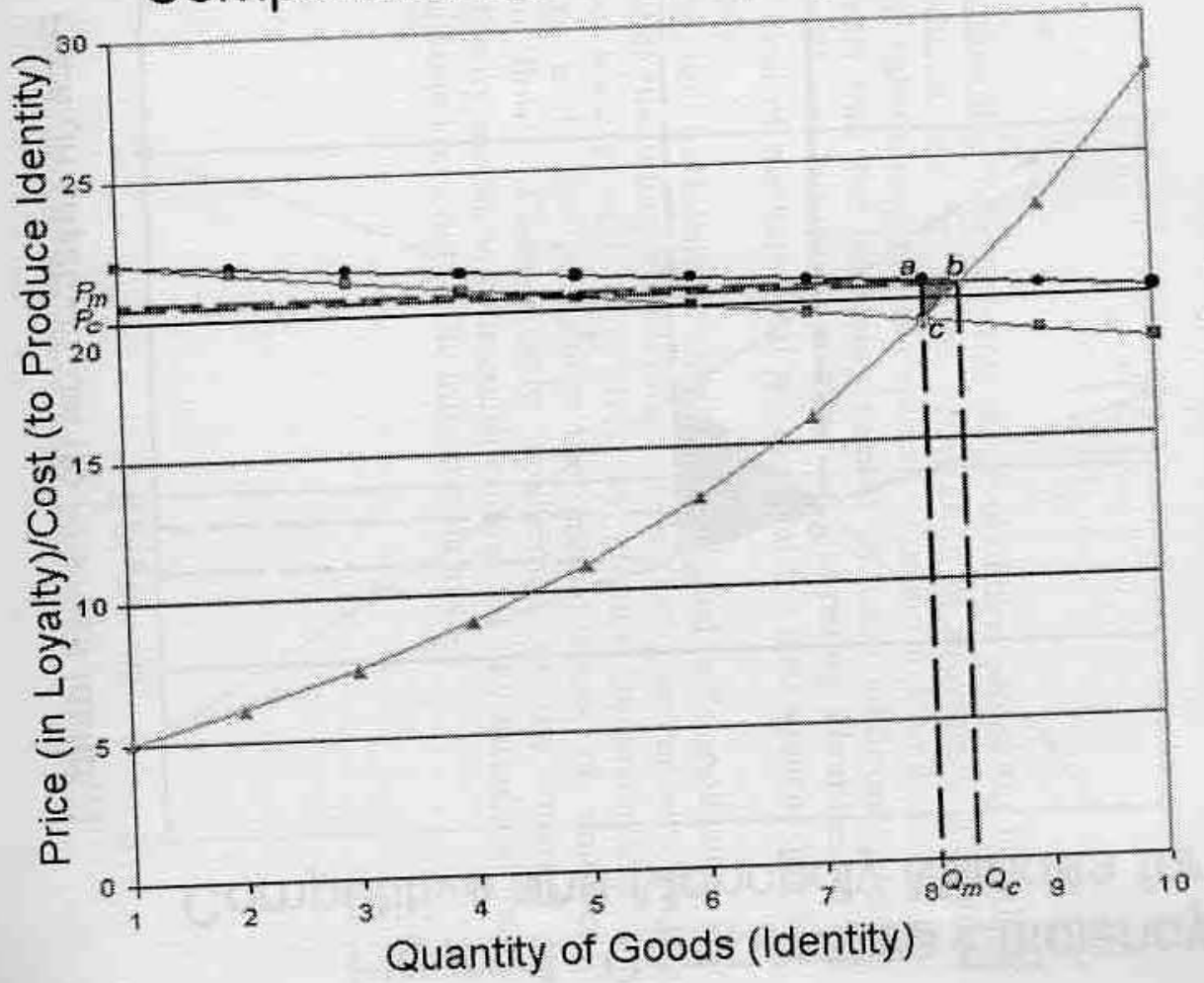

- Monopolist and industry Demand Curve

- Marginal Revenue

-Monopolist's

Marginal Cost

Curvelcompetitive

Supply Curve

Figure 3: China - Comparative Efficiency of Competitive and Monopoly Markets for Loyalties

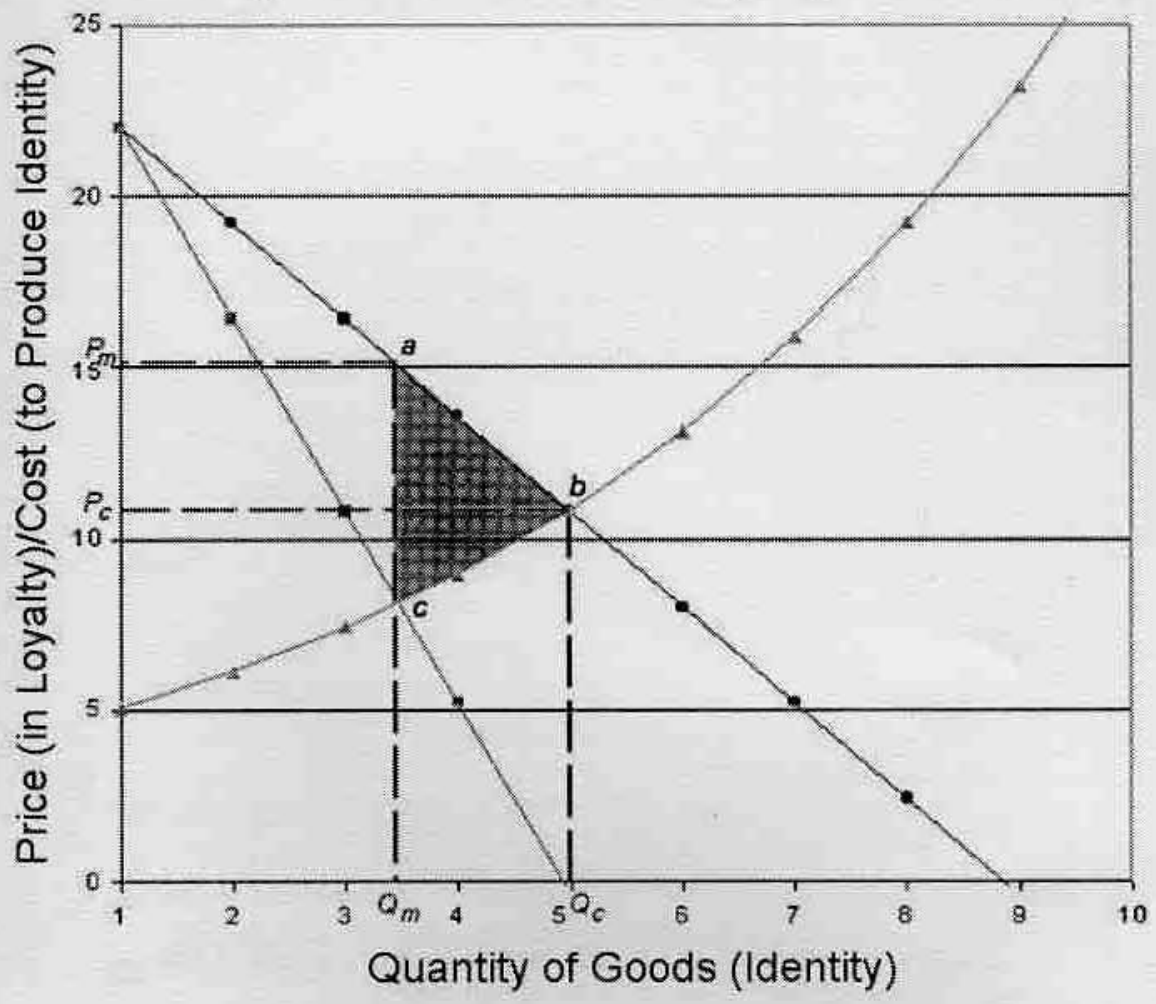

- Monopalist and Industry Demand Curve

- Marginal Revenue

- Monopolist's

Marginal Cost Curve/Competitive Supply Curve 